\title{
Animal Welfare: Could Adult Play be a False Friend?
}

\author{
Catherine Blois-Heulin ${ }^{1 *}$, Céline Rochais ${ }^{1},{\text { Sandrine } \text { Camus }^{2} \text {, Carole Fureix }}^{1}$, Alban Lemasson ${ }^{1}$, \\ Christophe Lunel ${ }^{1}$, Erwan Bézard ${ }^{2,3}$, and Martine Hausberger ${ }^{1}$
}

${ }^{1}$ Université de Rennes

${ }^{2}$ Université de Bordeaux

${ }^{3}$ China Academy of Medical Sciences, Beijing

*Corresponding author (Email: catherine.blois-heulin@univ-rennes1.fr)

Citation - Blois-Heulin, C., Rochais, C., Camus, S., Fureix, C., Lemasson, A., Lunel, C.,...Hausberger, M. (2015). Animal welfare: Could adult play be a false friend? Animal Behavior and Cognition, 2(2), 156-185. doi: 10.12966/abc.05.04.2015

\begin{abstract}
There is no consensus regarding the functions of play. As play behavior is a characteristic of young stages of development, it has been suggested that the higher prevalence of adult play observed in domestic animals could be the result of their "neotenic retardation." Functional hypotheses have dealt with the long term benefits, such as "rehearsal," "motor training" for future adult competencies or "training for the unexpected." However, there is little consistent experimental evidence favoring a particular hypothesis. The present study aimed to test the functional significance of adult play as a potential reliable indicator of good welfare, a by-product of domestication or a tool for social cohesion. Observations of both a domestic species (the horse) and wild/captive animals (cercopithecids) confirm the literature data that show the greater prevalence of adult play in the domestic/captive situations. This convergence between a domestic and a wild species argue against the idea that adult play may be a mere product of domestication. Moreover, animals living in naturalistic situations had the same low level of adult play as observed in wild animals suggesting that captive/domestic animals do not play only because they are stress free or well fed. Play is not a reliable indicator of welfare: Horses and adult macaques that played the most were also those that exhibited the greatest signals of poor welfare as stereotypic behaviors. Furthermore, adult play was more frequent at times of social disturbances and instability. Adult play is a sign showing that the adult organism needs to evacuate stress.
\end{abstract}

Keywords - Stereotypies, Life condition, Stress, Captivity, Horses, Rhesus macaques, Long-tailed macaques, Mangabeys, Campbell's monkeys

What is play behavior? There is no real consensus regarding the behavior definitions or functions of play. Even the English word "play" has many different meanings. "Play" relates to exploratory behavior, energetic activity, inhibition of behavior and young age (Burghardt, 2005). It is generally admitted that play is composed of normal elements of "functional" behaviors (aggressions, sexual interactions, exploration of objects, locomotion) that are produced in shorter bouts (e.g., Bekoff, 1995; Nunes, Muecke, Anthony, \& Batterbee, 1999), with exaggerated movements (e.g., prancing in foals, McDonnell \& Poulin, 2002) that are produced in a disorderly but repetitive manner and without any visible short term function (Burghardt, 2005; Byers, 1998). Thus play fighting does not lead to injuries. Animals have developed stereotyped signals that indicate that they want to play or to maintain play, and are not aggressive (e.g., bows of canids, Bekoff, 1995; "play face" of primates, van Hoof, 1967). Play signals are more visible and different in form from their "serious" equivalent (Yanagi \& Berman, 2014). Observers consider that animals are "having fun" (Spinka, Newberry, \& Bekoff, 2001, p. 144), by analogy with human play (Ciani, Dall'Olio, Tanyon, \& Palagi, 2012). Play occurs unpredictably. Its 
occurrence has no clear relationship with the immediate context (e.g., Burghardt, 2005), which makes it difficult to understand its possible function(s).

Play behavior is definitely and first of all a characteristic of young stages of development. For Coppinger and Smith (1989), play is a by-product of the offset of infantile behavioral systems interacting with the onset of adult behavioral systems, during the juvenile phase of development. It has been suggested that the higher prevalence of adult play that is observed in domestic animals could be the result of their neotenic retardation (Bekoff \& Byers, 1981). Buytendijk (1933, cited by Thinès, 1996) even proposed that invertebrates do not play because they lack juvenile stages. Finally, according to Byers and Walker (1995), play may appear sporadically later in life, but unpredictably and at low rates. Indeed, play is absent or rare in the behavioral repertoire of most adult wild animals and adult and young play often differ in form and in frequency (Nunes et al., 1999; Trezza, Baarendse, \& Vanderschuren, 2010). However, there are differences between species or phylogenetic groups. Adult carnivores are more likely to play compared to ungulates and tolerant species of primates are more likely to play compared to "despotic" societies (Ciani et al., 2012). Carnivores, once fed, have plenty of time and energy available for other "luxury" activities, such as play. In primates, play could help to reduce tensions and to keep social cohesion. Thus, many different functional hypotheses may apply to play behavior, because of its possible multifunctional quality on the one hand, and its lack of obvious short term benefit on the other hand. Since play behavior is first of all a juvenile feature, most functional hypotheses have dealt with the long term benefits, such as "rehearsal" or "motor training" for future adult competencies in the feeding or social context (Byers \& Walker, 1995; Gross, 1898), "training for the unexpected," when the young animal puts itself in situations of physical unbalance or loss in social encounters, in order to be ready for such unexpected situations in the future (Spinka et al., 2001). However, despite one century of research and more than 30 functional hypotheses (Baldwin, 1986), there is little consistent experimental evidence favoring a particular hypothesis (Blumstein, Chung, \& Smith, 2013; Pellis \& Iwaniuk, 1999). Play may have different functions in different species (Pellis \& Iwaniuk, 1999) and also at different stages of an animal life (Held \& Spinka, 2011). Adult play is especially interesting in this regard since benefits, if any, should be immediate or at least at short term (Burghardt, 2005; Palagi, Cordoni, \& Borgognini, 2004).

Interestingly, most studies on adult play imply, at some stage, a relationship with stress and arousal. Adult play behavior is associated with high arousal (Bekoff \& Byers, 1998), social stress situations (such as the introduction of a newcomer) (Antonacci, Norscia, \& Palagi, 2010) or feeding competition (Palagi et al., 2004) or would be a rebound effect after social or spatial deprivation (e.g., Wood-Gush, Vestergaard, \& Petersen, 1990). Even in young animals, the relationship between stress and play is complex. While in most cases, play is more present in young that are healthy, well fed, housed and securely attached (Fraser \& Broom, 1990; Hausberger, Henry, Larose, \& Richard-Yris, 2007; Henry, Richard-Yris, Tordjman, \& Hausberger, 2009; Henry et al., 2012; Jensen \& Kyhn, 2000) and tends to be suppressed by aversive conditions such as restricted access to maternal milk, maternal separation (piglets: Donaldson, Newberry, Spinka, \& Cloutier, 2002) or sickness (Fraser \& Broom, 1990), restricted feeding or maternal care (cats: Bateson, Mendl, \& Feaver, 1990; Bateson \& Young, 1981; Hall \& Bradshaw, 1998; horses: Cameron, Linklater, Stafford \& Minot, 2008; rhesus monkeys: Devinney, Berman, \& Rasmussen, 2003), social stress or isolation (polecats: Diener, 1985; hamsters: Guerra, Takase \& Nunes, 1999; rats: Smith, 1991; Panksepp \& Beatty, 1980; primates: Devinney et al., 2003; Lemasson, Gautier, \& Hausberger, 2005; O’Neill Wagner, 1994; Palagi, Paoli, \& Borgognini Tarli, 2006; Petit \& Thierry, 1994; domestic cats: Hall \& Bradshaw, 1998; domestic stallion: Christensen, Ladewig, Søndergaard, \& Malmkvist, 2002) may also trigger play. Interestingly, enrichment triggers play in piglets, when it occurs at 5 weeks of age, but not when it occurs at 19 weeks. Such observations have led to the suggestion that play may reduce stress or may act as a coping mechanism (Coe, Lubach, Ershler, \& Klopp, 1989) and may regulate stress (Palagi et al., 2004).

Although there is little evidence supporting this hypothesis, early theories (e.g., Carr, 1902) suggested that "circular and muscular reactions during play could remove toxic substances that build up in response to physical or mental work and stress." More recently, Spinka et al. (2001) suggested that play 
may favor "emotional resilience" and more and more authors wonder whether stressful situations may diminish play or, on the contrary, enhance it (Pellis \& Pellis, 2009).

Of course this contradicts the common view that play is suppressed by stress (Palagi et al., 2004) and is indicative of good welfare. Since the early hypotheses of Newberry and Wood-Gush (1988) and others, and in agreement with the statement that play is indicative of "having fun" (Spinka et al., p. 144), play behavior has been proposed as one of the three reliable indicators of good welfare (Boissy et al., 2007). According to Held and Spinka (2011), the occasional occurrences of adult play would indicate the well-being of the animals displaying it. However, one must pay attention to two aspects: a) causality and function have to be distinguished because they are often mixed up: a happy and stress free state may trigger play (causality) and/or play offers a beneficial outcome (function) (Pellis, Pellis, \& Reinhart, 2010) b) acute and chronic stress have to be distinguished: play diminishes in rats under acute restraint stress, but not under a repeated chronic stress (that nevertheless diminishes other social interactions) (Klein, Padow, \& Romeo, 2010). This may be especially true when rebound effects are considered: Rats and horses play more when they are placed with peers after a social isolation period (Christensen et al., 2002; Loranca, Terrero, \& Salas, 1999), calves and piglets play more when they are placed in larger pens (Jensen \& Kyhn, 2000; Mintline, Wood, de Passillé, Rushen, \& Tucker, 2012; Wood-Gush et al., 1990). While the individual is certainly excited and potentially enjoying an increased immediate "well-being," this does not mean that it is overall displaying a good welfare, what we mean a durable state of wellbeing. An alternative view is that, precisely because they are in poor welfare conditions, the individuals may require play to "eliminate toxic substances" (Carr, 1902) and the surplus of energy (Spencer-Schiller theory) and to perform a "self-medication" thanks to the endogenous opioids that are triggered by play (Pellis \& Pellis, 2009).

In the present study, we hypothesized that adult play may, as opposed to the dominant view, be a signal of potential altered welfare that animals try to compensate when given the opportunity. Two sets of facts support this statement:

- It is intriguing that adult play is present/more frequent in domestic or captive situations compared to wild/naturalistic conditions. This is something that reminds us of abnormal behaviors, such as stereotypies. If the increased adult play observed in domestic animals is due to selection for neotenic features (Coppinger \& Smith, 1989), there should be more differences between wild/feral animals and their domestic counterparts than between wild species under natural versus captive conditions. However, few studies have precisely compared (using the same sampling) the prevalence of play in the same species under such opposite conditions (natural/domestic; natural/captive). Therefore, in the present study, we will a) test the domestication hypothesis by comparing data obtained in a domestic species, the horse, between animals living in naturalistic conditions versus in the usual domestic conditions on one hand, to those obtained in a wild species (rhesus macaque) living in naturalistic conditions versus in intensive husbandry. Horses are interesting also because data are available from feral populations and the close wild Przewalski species, which all confirm the rarity of adult play in natural conditions. The choice of these two species is both opportunistic (data are available in the literature) and related to the fact that both express low levels of adult play in natural conditions while anecdotal reports indicate that it does occur in the domestic/captive situations. Although not close phylogenetically, if the pattern is the same in both species (more adult play in captive/domestic situation), then the effect of domestication through neoteny is not the primary explanation to the increased level of play observed in domestic animals. Thus, if the domestication hypothesis is not the sole explanation (e.g., both captive rhesus macaques and domestic horses show increased levels of adult play), then the alternative/complementary hypothesis would be that captive/domestic conditions may alter welfare and induce increased adult play. Thus, we will also b) test whether there is cooccurrence between indicators of poor welfare (e.g., stereotypic behaviors considered as reliable indicators of poor psychological wellbeing in primates by the International community of 
primatologist) and the prevalence of adult play in both horses and macaque species. If this hypothesis is confirmed, we will c) examine some of the possible factors that may be involved.

- Adult play seems to occur mainly in fluid tolerant social organizations (Mancini \& Palagi, 2009) and to be involved in tension reduction and social cohesion. We will study primates with different types of social organizations to investigate the effects of social instability and disturbances.

Most of the data used here have been the basis of published studies on horse and monkey welfare and/or social organization (Camus, Blois-Heulin, Li, Hausberger, \& Bezard, 2013; Camus, Rochais, et al., 2013; Camus et al., 2014; Hausberger, Fureix, Bourjade,Wessel-Robert, \& Richard-Yris, 2012; Lemasson et al., 2005; Lemasson, Blois-Heulin, Jubin, \& Hausberger, 2006).

\section{Adult Play: A Byproduct of Domestication or of Life Conditions?}

\section{Prevalence of Adult Play in Different Conditions}

The Insight from a Domestic Species: the Horse. Play behavior, locomotor, social or with objects, starts in foals a few hours after birth and peaks when they are about two weeks old (play occurs then 1 to 4 times per hour and represents 6\% of the time budget: Crowell-Davis, Houpt, \& Kane, 1987; Sigurjonsdottir, van Dierendonck, Snorrason, \& Thorhallsdottir, 2003). Young animals and two year old mares can spend $1.5 \%$ of their time playing (Sigurjonsdottir et al., 2003; Wells \& von GoldsmithRotschild, 1979), but play behavior is totally absent in the repertoire of adult mares, generally from their first foaling on three years of age (Feh, 2005; Feist \& McCullough, 1976). The young males, will generally join bachelor groups where social play, especially play fighting may reach $10 \%$ of their time budget (Bourjade, de Boyer des Roches, \& Hausberger, 2009; Hoffmann, 1985). However, play behavior decreases from the age of four and becomes a rare behavior mostly observed in winter and only in bachelor males (Hoffmann, 1985). Harem stallions do not play, apart from a few responses to solicitations from juveniles.

Play is frequently stimulated by novel conditions in foals as in young adult males (changes in weather, novel site) and is often interspersed with exploration. All studies agree to consider that play is absent in the repertoire of most adult horses living in natural conditions.

While all field studies agree on the quasi absence of play behavior in adult horses, reports of adult play are frequent in domestic or captive (e.g., Przewalski in zoo: Budiansky, 1997) situations.

\section{Material and Method} conditions:

We performed two sets of observations, to test the differences between horses living in different

- Five domestic horses (2 stallions and 3 geldings of mixed breeds: Haflinger, Fjord, Cross Haflinger, Irish cob type, Appaloosa; aged 7 to 17 years old) living in a stable group in naturalistic conditions (large pastures). This group was observed twice a month for 13 months during 2 hours. Play behavior was recorded ad libitum (Altmann, 1974). A total of $52 \mathrm{hrs}$ observations were recorded (i.e., 2 hrs every 15 days).

- $\quad$ Twenty-nine domestic horses (23 geldings and 6 mares; 26 of which were French saddlebreds; aged 7 to 17 years old) living in a riding center. They spent most of their non-working time in single stalls $(3 \times 3 \mathrm{~m})$ where they received three meals per day and hay once a day (see also Hausberger et al., 2012). They were used in classical riding school lessons for 4 to 6 hrs per week and they were released in bare (soil) paddocks in groups of about seven horses (always the same) on weekends for two $5 \mathrm{hrs}$ session in the morning. Four groups were observed (3 groups comprised of 7 horses and 1 group of 8 horses). Each group was observed twice, in sessions of 
one hour. Play behavior was recorded ad libitum (Altmann, 1974). In both cases, only social play was observed.

Play can easily be distinguished from "real" fights as the ears are never pinned back and the interaction lacks the vocalizations that are associated with real fights (Bourjade et al., 2009; McDonnell \& Poulin, 2002).

\section{Results (Figure 1A)}

The results on the domestic horses living in naturalistic conditions confirm data from feral animals and other natural conditions: Only 10 play bouts (social play) were observed over the 52 hrs observations, in three of the five individuals. Within these 10 bouts, 6 were observed in December, 2 in April and 1 in June and July respectively. There was no relation with age nor sexual status (1 out of 2 stallions, 2 out of 3 geldings involved).

The results were very different for the riding center horses: 22 of the 29 horses (only two mares out of 6 but 20 geldings) have played at least once ( $3 \pm 5$ SE in 2 hrs, 1 to 20 times). One horse played 20 times in $2 \mathrm{hrs}$, which is more than the play rate observed in foals in natural conditions. There was no correlation with age (Spearman correlation $r_{s}=0.02, N=29, p>0.05$ ).

\section{Conclusion}

These data clearly confirm previous data on feral and domesticated but free living horses: adult domestic horses living in naturalistic conditions rarely play compared to conspecifics living in a restricted domestic situation. These differences cannot be explained solely by domestication-induced neoteny although genetic differences could occur (Wolff \& Hausberger, 1994).

\section{A Wild Species in Captive Conditions: An Impact on Adult Play?}

Rhesus macaques are known for their "despotic" social system, which would explain the absence of adult play in natural conditions (Mancini \& Palagi, 2009; Thierry, 1985). We compared one large group of rhesus macaques living in naturalistic conditions with conspecifics living in an intensive system of breeding, using similar protocol of observation.

\section{Material and Method}

Naturalistic conditions. Fifteen adult females and five adult males (mean age unknown) were observed among 70 individuals in a zoo (Planète Sauvage, Nantes). The subjects lived in a large multimale multi-female group of ten males, 40 females and 30 sub-adults and juveniles, on a 2 ha area planted with trees and covered with grass. The group had been stable for several years at the time of the observations and no weaning was done until two years. The animals were fed with fruit, vegetables, and barley or bred once daily and had water ad libitum in a pond. The observations were done during one month in February 2011. We used individual scan-sampling (Altman, 1974) occurring every two minutes during the focal observations (i.e., 60 scans/individual). We assessed the individual behavior, posture, body orientation, location and distance to the nearest congener. Data were collected in a randomized order twice a day (morning and afternoon), outside of feeding times.

Breeding facility (Institute of Beijing Xierxin Biology Resource, China) (Camus et al., 2014). This facility produces macaques for pharmacological and medical laboratories. Weaning was done early at 6 months and the density of macaques was high. The animals lived in stable (> 1 year) single male groups (one male with eight or nine females) in an indoor/outdoor enclosure $\left(14 \mathrm{~m}^{2}\right)$. They were fed with monkeys pellets twice a day and fruit once a day. Thirty five females $(9.06$ years old \pm 0.6$)$ from 8 
different stable groups were observed in both conditions and their behaviors were recorded using a scansampling method, in which behavioral parameters were assessed every $6 \mathrm{~min}$, during $2 \mathrm{hr}$ sessions, resulting in 240 scans per female. For each group, data were collected in a randomized order twice a day (morning and afternoon) on 6 consecutive days. Following a 4-hr habituation phase performed one day before the beginning of the observations, macaque behavior was voice-recorded and scored live, by one trained observer, outside of feeding and cleaning times. The observations were performed during 2 months: September and October 2010.

For both populations, the observation methods were the same: scan sampling in the morning and in the afternoon, outside of feeding time and with the same observer (SC) in China and Nantes, but with another additional observer in Nantes (CR) (inter-observer reliability: Spearman rank order correlation $r_{s}$ $=0.86, p<0.05)$. Four categories of play were distinguished: social play, object play, water play and movement play.

\section{Results (Figure 1B)}

The results show that adult play occurred only in the intensive breeding situation, with 6 adult females exhibiting play behavior, at a rate from $0.41 \%$ to $2.31 \%(0.17 \% \pm 0.08 \mathrm{SE})$, while none of the females played in the naturalistic setting.
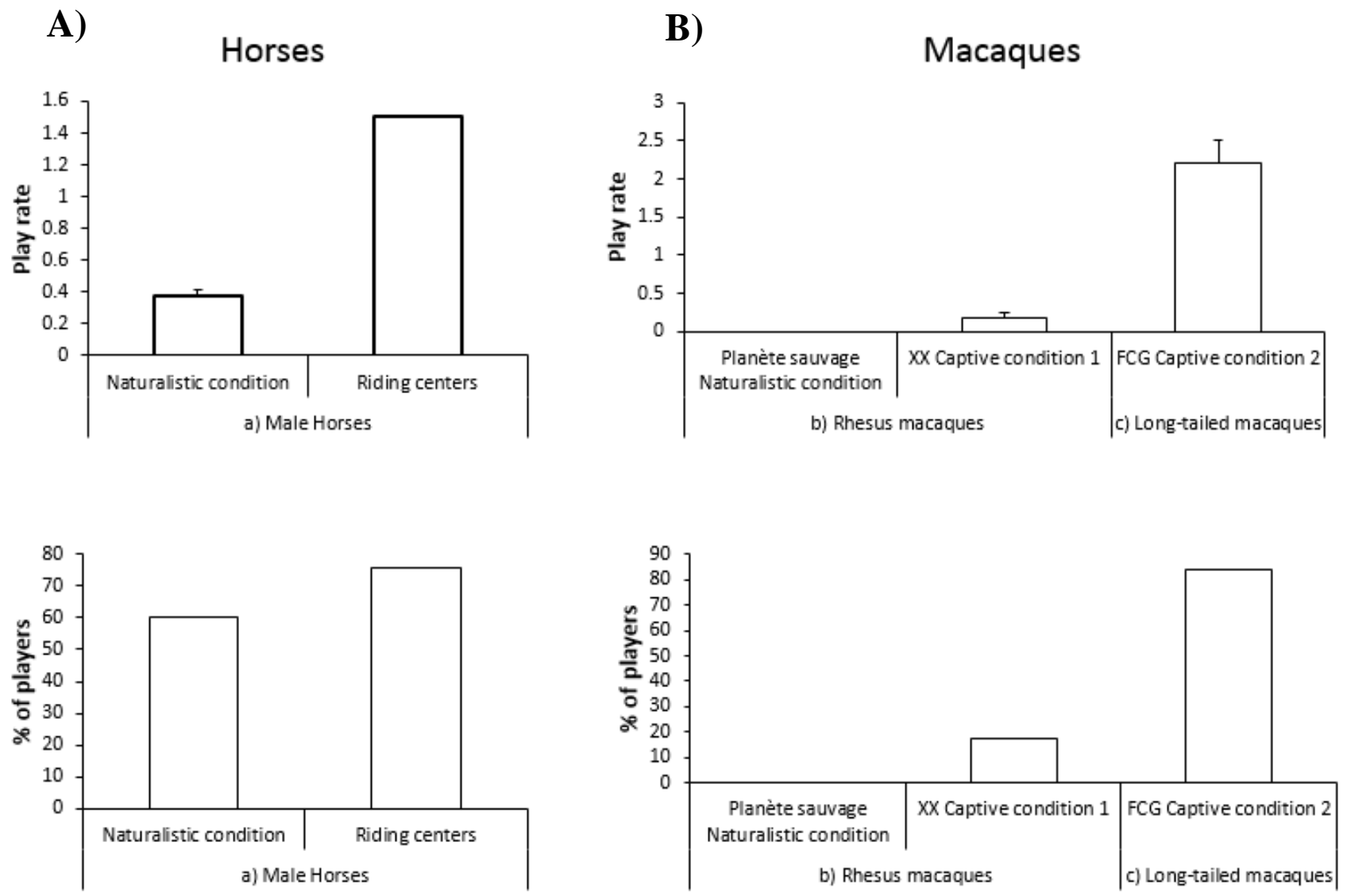

Figure 1. Variation of play rate (mean \pm SE and percentage of players (i.e., observed at least one performing the behavior) in male horses (A), rhesus, and long- tailed macaques (B) according to life conditions (naturalistic/domestic/intensive husbandry). Note. XX = Institute of Beijing Xierxin Biology Resource; FCG = Fang Cheng Gang facility 


\section{Conclusion}

This result clearly shows the impact of captivity on the prevalence of adult play in a wild species.

\section{Is Adult Play Triggered by Intensive Captive Conditions?}

Long-tailed macaques have a more tolerant social organization than rhesus macaques, so adult play should be more frequent in long-tailed macaques. However, the studies show possible but rare occurrences of adult play in natural conditions.

We had no access to a "reference" population of long-tailed macaques, so we studied the prevalence of adult play in intensive breeding facilities, and compared with data from the literature (Leon \& Taylor, 1993 cited in Crockett et al., 1995; Son, 2004). According to Son (2004), long-tailed macaques spend around $2.5 \%$ of their time in "other activities," including play behavior. Xu et al. (2012) reported that play behaviors occurred at a lower average daily count per subject $(1.22$, i.e., $0.20 \%$ of the total behaviors expressed by macaque) compared to other behaviors. In addition, in rhesus macaques, play is also a minor activity, representing around 5\% of the group activities (Bernstein \& Mason, 1963; Post \& Baulu, 1978), or less (1.13\%, Fisler, 1967). All these authors underlined that play is typically an activity of juveniles, even though adult males (lower ranking) sometimes play with juveniles and higher ranking males and females may play with infants (Post \& Baulu, 1978).

\section{Material and Method}

A total of 80 females (mean age: $5.9 \pm 0.1$ yrs old) from eight "harems" were observed during 2hr sessions, using a 6 min interval scan-sampling resulting in 240 scans per individual, at the Fang Cheng Gang facility (the Fangcheng Gang Spring Biological Technology Development Corporation, Guangxi province, China). The observations were performed in March and April 2010 (see also Camus, Rochais et al., 2013; Camus et al., 2014).

\section{Results}

The results show that most adult females played at least once $(68 / 80)$ with variable rates, from 0.42 to 13.87 . The mean rate of adult play $(2.2 \% \pm 0.32 \mathrm{SE})$ was equivalent to that observed in the wild for mixed age groups for behaviors including play (Son, 2004). Therefore, captive conditions, such as those observed in breeding facilities, seem to trigger adult play.

\section{Conclusion}

Adult long-tailed macaques played more in intensive breeding captive conditions compared to natural conditions. More than half of the captive animals exhibited play behaviors, which is much more than reported in field studies. Moreover the captive animals performed play at a quite high rate for adults.

\section{Conclusion: Domestication or Living Conditions?}

Both domestic species (the horse) and wild species (rhesus and long-tailed macaques) showed a different prevalence of adult play according to life conditions. This convergence between a domestic and a captive species is very interesting and suggests that the "neotenic hypotheses" (Coppinger et al., 1987) can not entirely explain why adult animals play more in restricted conditions. This hypothesis may apply better to pet species, such as dogs or cats, that may have been selected in this direction, in order to exhibit attractive features (amongst which play) and less fear of humans, but it does not explain why such an increase in play is observed in wild species that were not selected for such traits. 
It is generally admitted that adult captive animals play more because they are stress free, having no predation pressure nor need to search for food (Burghardt, 2005; Graham, 2010). This is possible because experiencing less fear and having more time and energy for non-vital activities could lead to an increase of "luxury" behaviors, such as play. Nevertheless, we have shown that even domestic animals, when they are maintained in naturalistic situations, but predator free and with food available, exhibit low level of adult play, like in the field situation. Thus, this is not just a matter of being careless and full of energy. In fact, the conditions where increased adult play is observed seem to correspond to situations where food, space and social contacts are restricted and where life experiences (e.g., early weaning) are often stressful (Table 1).

Many factors concur to alter the animal welfare in these conditions and this higher prevalence of adult play, which reminds us of the higher prevalence of abnormal behaviors, such as stereotypies, in these same situations, questions the possible relation of adult play with welfare states.

Table 1

Characteristics of Horse's Life Conditions
Natural Conditions
Domestic Conditions (predominant)

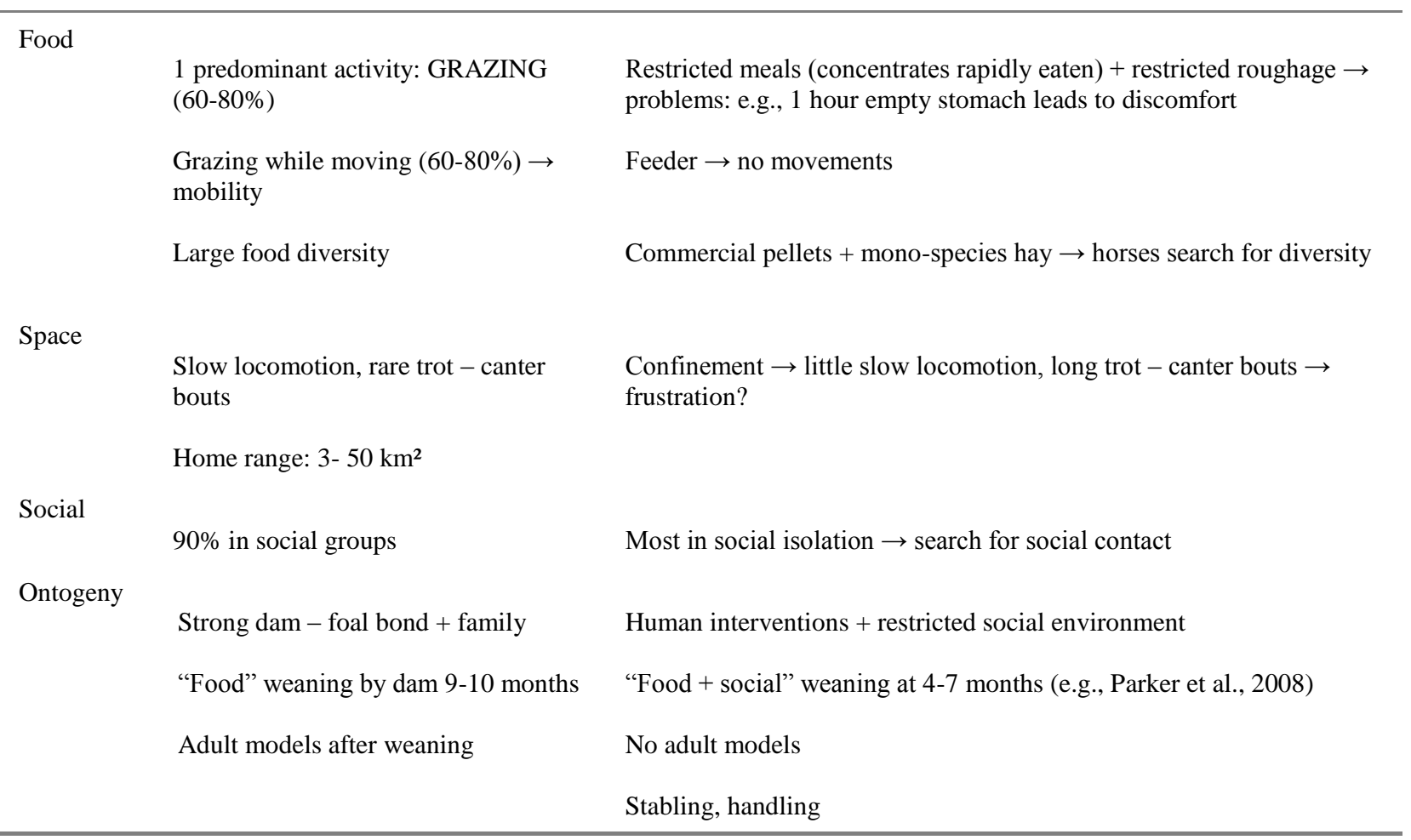

\section{Co-occurrence of Adult Play and Welfare Indicators}

We asked whether or not adult play may be a way of coping with stress. The first unsolved question is whether play may be triggered by stressful situations, or whether it may be, as generally admitted, an indicator of a stress free situation. The separation between acute stress, that indeed may indeed suppress play in all cases, and chronic stress, that may lead to altered welfare states, is particularly important here. When playing we expect animals to experience positive emotions, triggered by the underlying neurotransmitters (Trezza et al., 2010), but this may not reflect their chronic welfare state that results from their daily experiences. Both stereotypic behaviors and play are associated with endogenous opioids (Burghardt, 2005), but it is generally admitted that stereotypic behaviors reflect inappropriate living conditions (Mason \& Latham, 2004; Mason \& Rushen, 2006). 
Testing the hypothesis that adult play may reflect altered welfare is difficult because play is a highly pleasurable behavior at the moment of its performance. Thus, we chose to look at possible cooccurrence between adult play prevalence or rate and reliable indicators of poor welfare.

Adult Play and Welfare in Riding School Horses Domestic horses face a set of challenges in the usual riding school settings (see Table 1), which results in physical and psychological disturbances (see also Hausberger et al., 2012). Vertebral problems are often underestimated, while they are a major and highly common problem (Fonseca et al., 2006; Jeffcott, 1980; Lesimple, Fureix, Biquand, \& Hausberger, 2013). Recent studies, as well as veterinarian reports, showed that horses with more vertebral problems, hence chronic discomfort, are more aggressive towards humans (Fureix, Menguy, \& Hausberger, 2010). Aggressiveness reflects altered well-being in humans (Anderson \& Bushman, 2002) as well as pigs (Day, de Weerd, \& Edwards, 2008; Turner, Ewen, Rooke, \& Edwards, 2000). We used it here as one indicator of altered welfare. The horses were submitted to standardized human-animal relationship tests (e.g., Fureix, Jégo, Sankey, \& Hausberger, 2009; Hausberger, Roche, Henry, \& Visser, 2008) and the occurrence of aggressive behaviors (threats) was recorded.On the other hand, likely because they repeatedly face unavoidable stress, horses may develop a "depressive-like syndrome," becoming withdrawn and unresponsive to environmental stimuli (Fureix, Jégo, Henry, Lansade, \& Hausberger, 2012; but see also Burn, Dennison \& Whay, 2010; Hall, Goodwin, Heleski, Randle, \& Waran, 2008). The horses tend to face the wall. Their unresponsiveness can be demonstrated through tactile stimulation using von Frey filaments (Fureix et al., 2012).

Horses, like many other species, also exhibit abnormal repetitive behaviors (ARB) in inappropriate settings. The prevalence of stereotypies and other ARB in horses has been shown to relate to frustration related to restricted roughage availability, space and social restriction, in addition to early stresses (such as early weaning) or to working conditions (e.g., Hausberger, Gautier, Biquand, Lunel, \& Jégo, 2009; McGreevy, Cripps, French, Green, \& Nicol, 1995; Mills, 2005). Thus, we performed observations of the horse's behavior in their stall.

Possible physiological correlates of altered welfare are more difficult to assess. "Classical" measures of plasma or fecal cortisol do not reliably account for the expression of stereotypic behaviors in horses (Fureix et al., 2013). Nevertheless, this remains a common way to estimate welfare in farm animals (Mormède et al., 2007), so we measured it here.

Finally, there is a novel approach of profound alterations of welfare: the measure of oxidative stress that occurs when antioxidant defense is overwhelmed, in relation with muscular tiredness and disorders, immune disorders, inflammatory and degenerative pathologies and stress (De Moffarts, Kirschvink, Pincemail, \& Lekeux, 2005).

We tested the potential relationship between adult play and this array of indicators on the 29 riding school horses that lived in restricted conditions but were released in groups twice a week.

\section{Material and Method}

As mentioned above, the twenty nine horses belonged to a same riding school, were living daily in single stalls but were released on the week-ends during two $5 \mathrm{hr}$ sessions, in a bare paddock, where we performed the observations of play behavior (for more details see Hausberger et al., 2012).

In their usual stall, and in periods of quietness in the school, the horses were submitted to:

- 5 human-horse relation tests: motionless person, approach, sudden approach, saddle and halter fitting and all the behaviors directed towards humans were recorded, with a special emphasis on aggressiveness

- behavioral observations: 6 sessions of $5 \mathrm{~min}$ continuous observations, as well as 3 sessions of $1 \mathrm{hr}$ instantaneous scan sampling (scan every $2 \mathrm{~min}$ ) were performed for each horse (with special emphasis on abnormal repetitive behaviors and orientations) 
- tactile reactivity tests using von Frey filaments that induce trembling when applied (Lansade, Pichard, \& Leconte, 2008)

- blood sampling that allowed cortisol measurements, as well as measures of oxidative stress using spectrophotometry (Corino, Rossi, Musella, Cannata, \& Pastorelli, 2007)

To obtain a more integrative evaluation of horse welfare, we calculated a score based on the behavioral indicators (physiological measures could have a non-linear relation with chronic stress). A total Chronic Stress Score (TCSS) was calculated, based on the ranking of the horses for the behavioral, sanitary (vertebrae) and reactivity (tactile) measures.

\section{Results}

The frequency of play was correlated with the total chronic stress score, the aggressiveness towards humans but also with the oxidative stress value. Players ( $\mathrm{P}$ - in paddock) differed from nonplayers (NP) on a variety of welfare indicators measured in the stall, including back disorders, aggressiveness towards humans, orientation towards the wall, tactile reactivity, as well as oxidative stress measures (Figure 2). There was no difference in the cortisol levels, which is not surprising given the complex relation between cortisol evaluations and chronic stress in horses. There was also no clear link between adult play and stereotypic behaviors, although these were included in the TCSS that differed between players and non-players. Positive correlations between play frequency and aggressive behavior, oxidative stress and total chronic stress score were found (Figure 3).
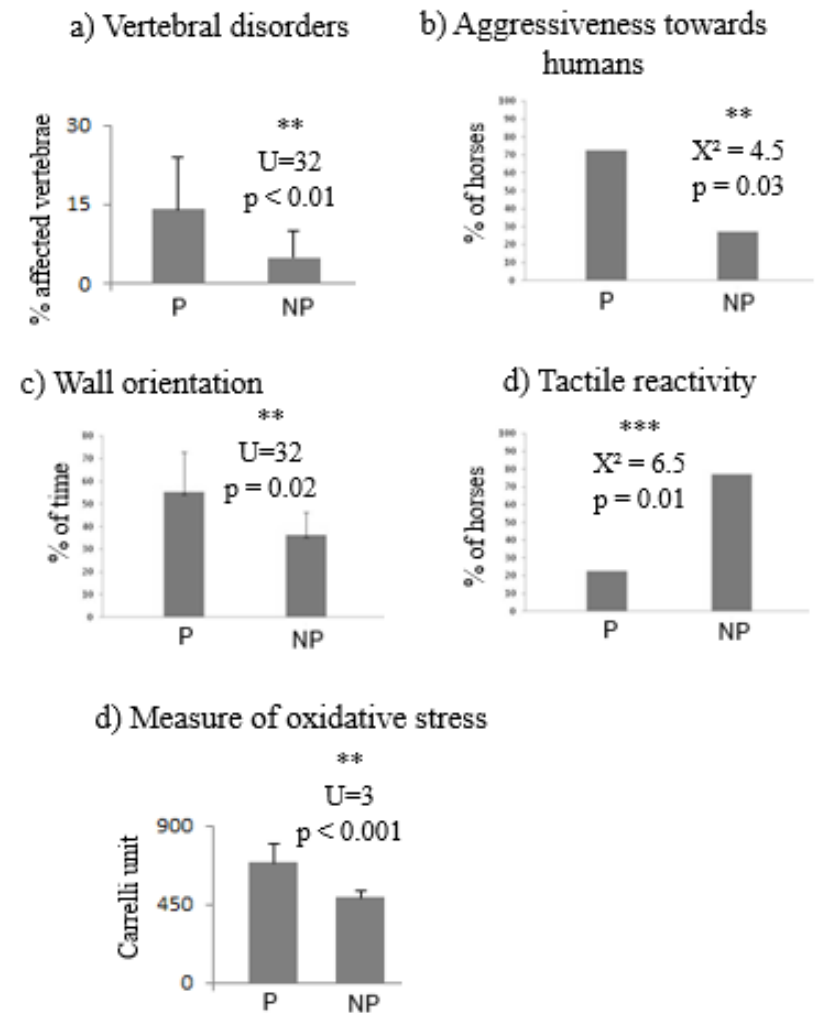

Figure 2. Relations between welfare and play indicators in horses. Welfare indicators measured in box for "players" horses (i.e., at least one occurrence in 2 hours; P) and "non-players" horses (NP). Vertebral disorder: number of reached vertebral site, mean $\pm \mathrm{SE}$ ), aggressiveness toward humans during standardized tests: \% of horses threatening the experimenter at least one, Horses orientation in their box: mean $\%$ of scan spent facing a wall $\pm \mathrm{SE}$; reactivity to touching chest: $\%$ of horses reacting at least one; measure of oxidative stress: mean $\pm \mathrm{SE}$, Carrelli unit. Chi-square and Mann-Whitney tests: $* p<0.05, * * p<0.01, * * * p<0.001$. From Hausberger et al. (2012). 


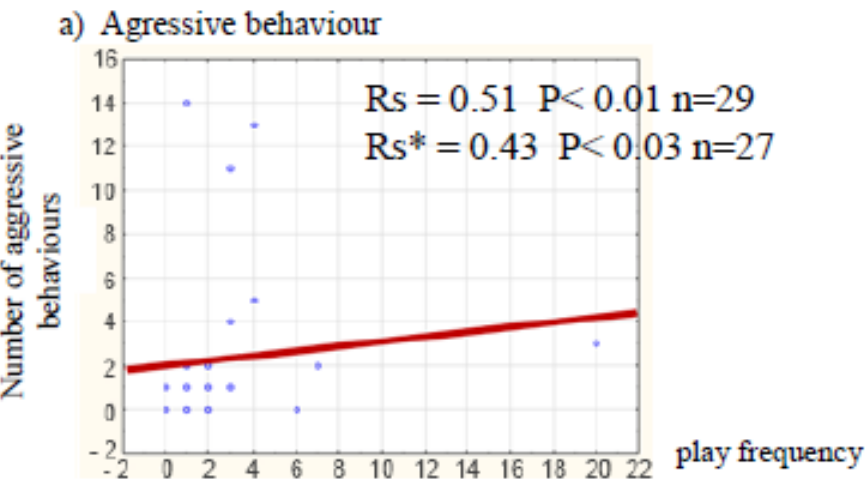

b) Oxidative Stress

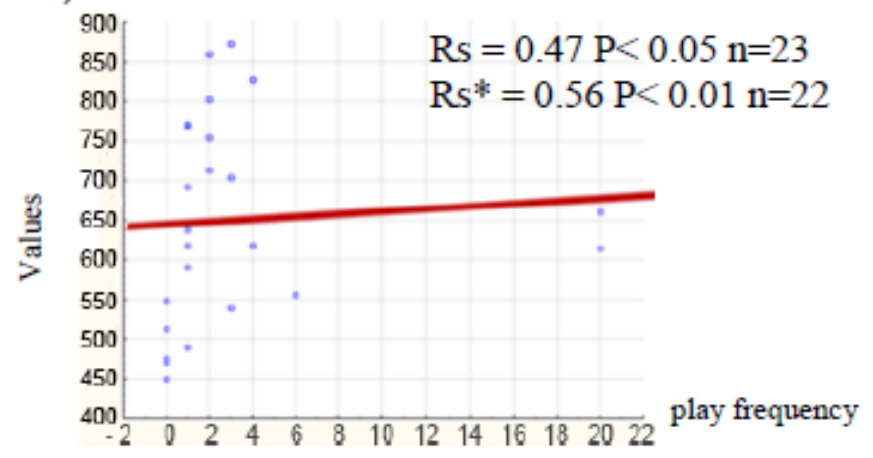

c) TCSS

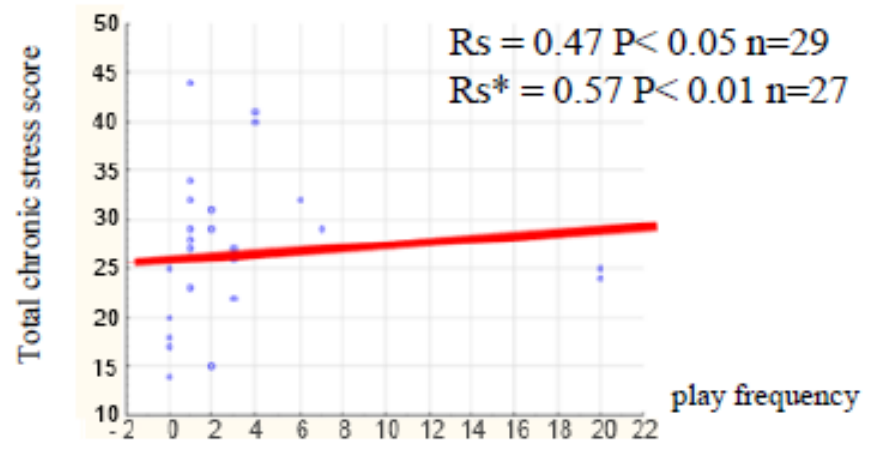

Figure 3. Relations between welfare and play indicators in horses. Spearman correlations between play frequency and aggressive behavior, measure of oxidative stress and total chronic stress score (based on the ranking of the horses for the behavioral, sanitary and reactivity measures, the higher the score is, the more stressed the horse is, Hausberger et al., 2012). Note that a similar pattern of results appeared when similar analyses were performed but excluding the two extreme outliers $\left(\mathrm{r}_{\mathrm{s}} *\right)$.

\section{Conclusion}

Both rate of play, but also the presence/absence of this behavior in the repertoire of the adult horses could be related to measures of altered welfare. It seems that adult players are the individuals that suffer the most from the restricted conditions of the current riding school living conditions. Social play in paddocks may be a mere rebound effect (which would also indicate that the usual situation does not satisfy the primary needs), but this would not explain the differences observed between players and nonplayers in terms of welfare. One explanation could be that play may help coping with the poor welfare state (e.g., Oliveira, Rossi, Silva, Lau, \& Barreto, 2010) and enable temporary emotional resilience (Spinka et al., 2001). Hausberger et al. (2012) suggested that the Carr's "recuperation theory" could make sense here, given the strong relationship with oxidative stress: the most affected horses could use play, 
when given the chance, to momentarily "escape" from stress, by using "muscular and circular actions to remove toxic substances build up in response to physical and mental work" (Burghardt, 2005, p. 36). Indeed, play could increase oxygenation through muscular exercise (Byers, 1998). While it is certainly pleasurable at the precise time of play, adult play in horses (especially when occurring at high rates) seems to indicate that the animal is "evacuating" excess stress rather than being a reliable indicator of welfare.

\section{Stereotypic Behavior and Adult Play: A co-occurrence in Primates?}

While in farm animals the status of stereotypic behaviors (STB) in terms of welfare assessment is regularly debated, stereotypic behaviors have been recognized as being a reliable indicator of poor welfare in captive primates by the International Primatological Society in 1993 (Crockett et al., 1995). Earlier studies have tried to relate derived activities with STB in primates (Reamer, Tooze, Coulson, \& Semple, 2010) or in other mammals (Fureix, Gorecka-Bruzda, Gautier, \& Hausberger, 2011) or have based the assessment of stress on activities such as self-scratching (Norscia \& Palagi, 2011). Mancini and Palagi (2009) found that play behavior and allogrooming were more frequent in the pre-feeding periods and concluded that play may be used to release tensions in such situations that are characterized by conflicts of interest. The increase of excitement due to the anticipation of food or reward arrival is well known to increase the rate of STB in horses (Fureix et al., 2011) but also locomotor play in piglets (Dudink, Simonse, Marks, de Jonge \& Spruijt, 2006). In a study on horses, Fureix et al. (2011) showed a co-occurrence between yawning and STB: The rates were correlated in some populations of horses, but could also just occur mostly in the same circumstances such as the pre-feeding period or periods without roughage. These findings do not lead to causal explanations, but provide hints about common factors of causation (e.g., frustration in this case).

Therefore, we investigated the possible co-occurrence of adult play and stereotypic behaviors in captive rhesus and long-tailed macaques living under intensive husbandry conditions (see above). There are reasons to believe that the two categories of behaviors may be related: they are both quasi absent of the repertoire of these species in natural conditions and they are both related to the release of endogenous opioids and to basal ganglia and striatum brain structures (Graham, 2011; Normansell \& Panksepp, 1990; Pellis \& McKenna, 1992; Trezza et al., 2010; Trezza, Damsteegt, Achterberg, \& Vanderschuren, 2011).

\section{Material and Method}

Thirty-five female rhesus macaques and 118 female long-tailed macaques were observed in three facilities that breed monkeys for laboratories (see also Camus et al., 2014). The conditions of life have been described earlier. All the rhesus macaques were at Xierxin (China), belonged to 8 groups composed of one male with 8-9 females. Eighty female long-tailed were at Fang Cheng Gang (China), belonged to 8 groups composed of one male with 17-27 females, and 38 female long-tailed, belonged to 10 groups composed of one male with 10-20 females, were at Haikou (Hannan Jingang Laboratory Animal Corporation, Hannan Province, China). All groups have been stable for at least 9 months, all the females were adult $(7 \pm 0.4 \mathrm{yrs}$ old; from 4 to $21 \mathrm{yrs}$ old $)$. The facilities differed in some aspects of management (Table 2), which led us to compare the female behavior in the two facilities for long-tailed macaques. Socially-housed female macaque behavior was scored following the same protocol, whatever the facility, and recorded live by one (in Xierxin and Haikou; SC) or two (in Fangcheng Gang SC and CR) trained observers (inter-observer reliability: Spearman correlation $r_{s}=0.86$ ). Colored medals were added to the monkeys' collar to facilitate the identification of the females using gentle restraint. The observations occurred outside of the feeding and cleaning times. For each group, the data were collected using exactly the same protocol as the one described earlier resulting in 216 scans per female in Xierxin and 240 scans per female in Fang Chen Gang and Haikou. Different types of stereotypies were observed, such as motor stereotypies, oral stereotypies and manual stereotypies (Table 3). 
Blois-Heulin et al. 168

Table 2

Comparison of the Different Macaque Facilities

\begin{tabular}{|c|c|c|c|}
\hline & Xierxin & Haikou & FCG \\
\hline Animals & $\begin{array}{l}2000 \text { Rhesus macaque } \\
500 \text { long-tailed macaques }\end{array}$ & $\begin{array}{l}17700 \text { long-tailed macaques } 30 \\
\text { Rhesus macaques }\end{array}$ & 8000 long-tailed macaques \\
\hline Origin & $\begin{array}{l}60 \% \text { captive-born, } 40 \% \text { wild- } \\
\text { caught }\end{array}$ & Captive-born and wild-caught & Captive-born and wild-caught \\
\hline Breeding groups & $1 \mathrm{M} / 8-10 \mathrm{~F}$ per cage & $1 \mathrm{M} / 17 \mathrm{~F}$ per cage & $1 \mathrm{M} / 17-27 \mathrm{~F}$ per cage \\
\hline Weaning & 5 months old & 6 months old & 3-4 months old \\
\hline Peer-housing & $\begin{array}{l}\text { Until } 7 \text { months: group of } 10 \text { to } \\
20 \text { young }\end{array}$ & $\begin{array}{l}\text { Until } 7 \text { months: groups of } 4-5 \\
\text { young } \\
\text { Possibility for the young to go } \\
\text { back with its mother }\end{array}$ & $\begin{array}{l}\text { Until } 4-5 \text { months: groups of } 2-3 \\
\text { young with special pellets }\end{array}$ \\
\hline $\begin{array}{l}\text { Post peer-rearing } \\
\text { housing }\end{array}$ & $\begin{array}{l}7 \text { months old: } \\
\text { Group of } 100 \text { young } \\
\text { 3-year old: } \\
\text { Males: single cage } \\
\text { Females: breeding groups }\end{array}$ & $\begin{array}{l}7 \text { month old: groups of } 15 \text { young } \\
18 \text { months: groups of } 30-40 \text { young } \\
\text { 3-year old: } \\
\text { Males: single cage } \\
\text { Females: breeding groups }\end{array}$ & $\begin{array}{l}\text { 4-5 months: largest cage } \\
\text { 3-year old: breeding groups }\end{array}$ \\
\hline Diet & $\begin{array}{l}3 \text { times per day Pellets/ } \\
\text { fruits/pellets }\end{array}$ & $\begin{array}{l}4 \text { times per day } \\
3 \text { times with pellets and } 1 \text { time } \\
\text { with vegetables and fruits }\end{array}$ & $\begin{array}{l}3 \text { or } 4 \text { times per day: } \\
2 \text { or } 3 \text { times with pellets and } 1 \\
\text { time with fruits }\end{array}$ \\
\hline Catching technic & $\begin{array}{l}\text { With a net alone or with } \\
\text { mother }\end{array}$ & With a net, with mother & With a net, with mother \\
\hline Cage Cleaning & Every 2 days & Twice a day & Once a day \\
\hline Enclosure & $\begin{array}{l}\text { Males: indoor single cage } \\
\text { Breeding groups: outdoor and } \\
\text { indoor enclosures }\end{array}$ & $\begin{array}{l}\text { Males: indoor single cage } \\
\text { Breeding groups: large enclosure } \\
\text { Large access to the indoor } \\
\text { enclosure }\end{array}$ & $\begin{array}{l}\text { Breeding groups: dark } \\
\text { enclosure, indoor enclosures } \\
\text { with a partially wired roof }\end{array}$ \\
\hline Natural lighting & $\begin{array}{l}\text { Males: through windows } \\
\text { Breeding groups: through } \\
\text { wire-mesh roof }\end{array}$ & $\begin{array}{l}\text { Males: through windows } \\
\text { Breeding groups: through wire- } \\
\text { mesh roof }\end{array}$ & Through wire-mesh roof \\
\hline Weighting & $\begin{array}{l}\text { Breeders: once a year } \\
\text { Isolated males: every } 2 \\
\text { months }\end{array}$ & $\begin{array}{l}\text { Breeders: once a year } \\
\text { Exported animals: twice a month }\end{array}$ & $\begin{array}{l}\text { Breeders: once a year } \\
\text { Isolated males: at least twice a } \\
\text { year }\end{array}$ \\
\hline Others & $\begin{array}{l}\text { Group composition changing } \\
\text { once a year }\end{array}$ & $\begin{array}{l}\text { One animal keeper per group, } \\
\text { always the same, bottle feed } \\
\text { babies if necessary }\end{array}$ & \\
\hline
\end{tabular}


Table 3

\begin{tabular}{ll} 
Description of the Different Stereotypies Observed \\
\hline Sterotypies & Description \\
\hline Manual Stereotypies & Manipulates collar repetitively \\
& Manipulates other object repetitively \\
& Picks peer's or own fur repetitively and outside grooming context \\
\hline Oral Stereotypies & Gnaws bars repetitively \\
& Licks bars repetitively \\
& Licks own tail or other body part repetitively \\
& Bites own tail or other body part repetitively \\
& Pepetitive tongue movement or tongue chew \\
& Self-suckling \\
& Pacing \\
Motor Stereotypies & Flipping \\
& Walks backwards
\end{tabular}

Note. Based on Brent \& Viera, 2002; Crockett et al., 1995

\section{Results}

Prevalence of STB and Adult Play (Figure 4). Rhesus macaques. The two categories of behaviors were observed in all the facilities. As mentioned earlier, 6 rhesus macaques in Xierxin performed play, with a rate of $1 \% \pm 0.30 \mathrm{SE}$ (from 0.46 to $2.31 \%$ of scans). Thirty-one individuals (88.6\%) performed a stereotypic behavior with rates of $3.16 \pm 0.64 \%$ of time budget (from 0.46 to $18.52 \%)$. All the players performed stereotypies as well. The players performed more STB than the nonplayers (Mann-Whitney-U test $N=6,25, \mathrm{Z}=-2.22, p=0.02$ ). The rates of adult play and stereotypic behaviors were correlated (Spearman correlation: $N=35, r_{s}=0.43, p<0.05$ ), and both were respectively negatively correlated with resting behavior (Spearman correlation: $N=35, r_{s}^{\mathrm{STB}}=-0.35 ; r_{s}^{\mathrm{PLAY}}=-0.37, p$ $<0.05)$.

Long-tailed macaques. Similar findings were found in long-tailed macaques in Fang Cheng Gang, where $67(83.75 \%)$ females were observed playing, with a rate of $2.62 \% \pm 0.37 \mathrm{SE}$ (from 0.42 to $13.87 \%$ ) and 57 females (71.25\%) expressed stereotypic behaviors, which is more than half of the females observed, with a rate of $5.40 \% \pm 0.93$ SE (from 0.42 to $33.61 \%$ ). Play and STB rates were correlated (Spearman correlation, $N=80, r_{s}=0.41, p<0.05$ ) and there were more stereotypic individuals amongst the players than amongst the non-players (Chi-square test, $d f=1$, Chi-square $=32.44, p<0.0001$ ).

There was a site differences as there were fewer individuals playing $(N=14,36.84 \%$ with a rate of $1.67 \% \pm 0.39 \mathrm{SE})$ and performing STB $(N=13,34.21 \%$ with a rate of $1.72 \pm 0.45 \mathrm{SE})$ in the Haikou facility compared to FCG (Chi square test: $\mathrm{df}=1 \mathrm{X}^{2}=6.36, p=0.011$ ). They also performed STB at a lower rate (Mann-Whitney test: $\mathrm{N}_{\mathrm{FCG}}=80 \mathrm{~N}_{\mathrm{H}}=38$, STB: $Z=4.01, p<0.0001$, Play: $Z=4.48, p<$ 0.0001 ). There was no correlation between play and STB in Haikou (Spearman correlation: $N=38, \mathrm{r}_{\mathrm{s}}=$ $0.05, p>0.05)$. STB rates were negatively correlated with immobility (Spearman correlation: $N=38, \mathrm{r}_{\mathrm{s}}=$ $-0.50, p<0.05)$.

The co-occurrence between adult play and STB is striking: there were clear correlations between the two categories of behavior, for the two species and in two facilities (Xierxin and Fang Cheng Gang). Adult players had greater chances to also be stereotypic. Moreover, one facility appeared different in terms of the welfare state of the animals (as shown by the much lower prevalence of STB) and also appeared to have a lower prevalence of adult play. 

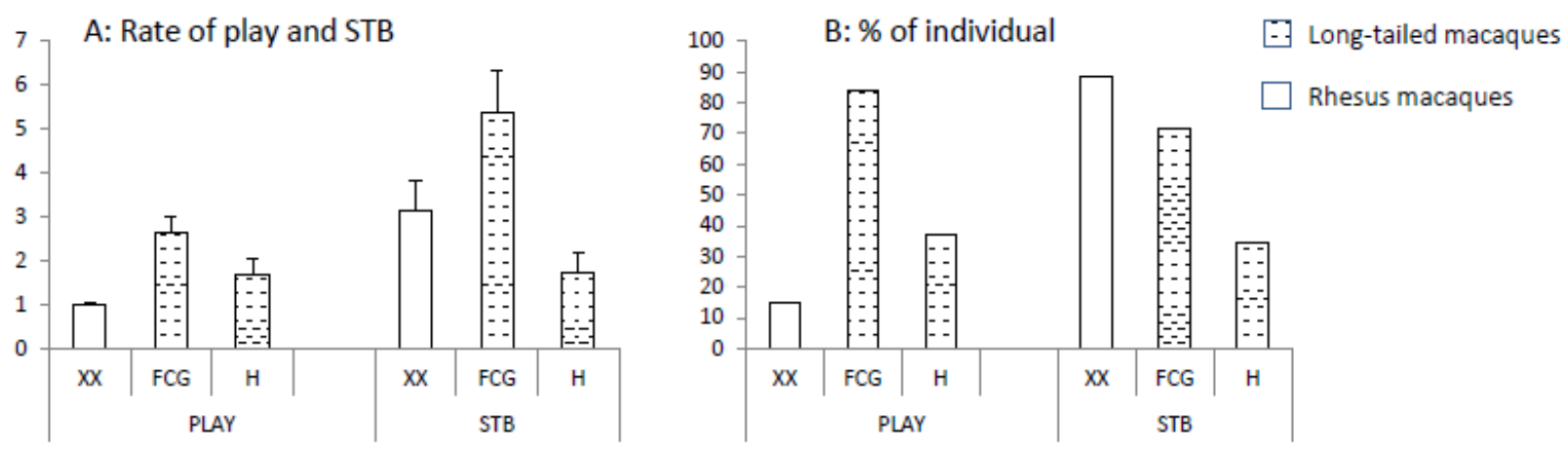

C: Correlations beween play and stereotypies frequencies
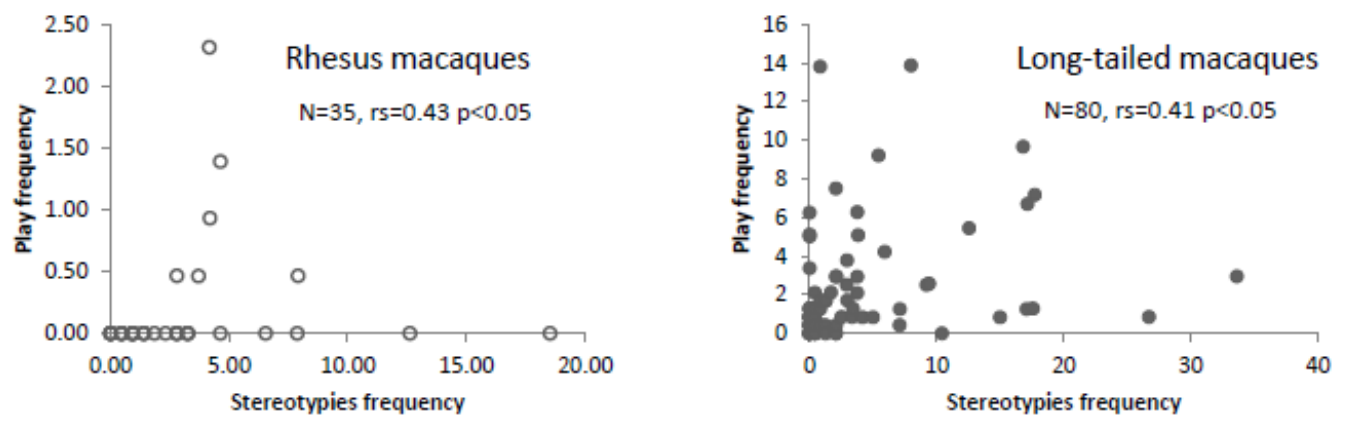

Figure 4. Effect of monkey species and facility on the prevalence and rate of play and stereotypic behaviors (STB) (means \pm SE). A) Comparison of rate (\% time budget) revealing higher rates of both play and STB in Fang Cheng Gang facility (FCG) longtailed macaques. B) Prevalence (\% of individuals that performed the behavior at least once) showing a species difference (less players and more stereotypic individuals in Xierxin rhesus macaques), but also a facility effect (FCG long-tailed macaques showed a higher prevalence of both adult play and STB than Haikou macaques). C) Correlations between adult play and STB in rhesus and long-tailed (in FCG) macaques.

Effects of early experience (Camus, Rochais et al., 2013). Some reports suggest that a "normal ontogenesis" may protect from later challenging situations, which would explain the lower prevalence of stereotypies in wild born animals (chimpanzees: Davenport \& Menzel, 1963; macaques: Mason \& Green, 1962). Social deprivation and maternal separation are considered as major causes of emergence of abnormal behaviors in primates (Khan, 2013; Martin, 2002). According to Novak, Meyer, Lutz, and Tiefenbacher (2006), all socially raised monkeys that show self-mutilation have been separated from their mother before the age of 2 years. However, the relation between early care and play at adolescence is complex: while in most species, young animals are more likely to play when well fed and securely attached (e.g., Henry et al., 2009); in rats, low maternal licking and grooming (an indicator of maternal care) is associated with an increased rate of play at adolescence (Van Hasselt et al., 2012) and in feral horses, foals of low condition mares play more than those of high condition mares (Cameron et al., 2008).

Here we observed (see above) differences in the prevalence of play in long tailed macaques between facilities. Interestingly, the only major difference between facilities was early experience as the timing and type of weaning differed (Table 4). 
Table 4

Life Conditions in Wild and Captive Macaques, Captive Macaques Under Intensive Husbandry

\begin{tabular}{|c|c|c|}
\hline & Wild Macaques & Milieu Captive Macaques \\
\hline Individual ontogenesis & $\begin{array}{l}\text { Long lasting association between young } \\
\text { and its mother } \\
\text { Weaning at } 1 \text { year } \\
\text { Food weaning } \\
\text { Social diversity }\end{array}$ & $\begin{array}{l}\text { Interrupted association between young } \\
\text { and its mother } \\
\text { Weaning at } 5 \text { months } \\
\text { Social AND food weaning } \\
\text { Groups of same age young } \\
\text { Social changes }\end{array}$ \\
\hline Food & Foraging behavior all day along & Time limited meals \\
\hline Habitat & Diversified & Homogeneous \\
\hline Group composition & $\begin{array}{l}\text { Multimale Groups - around } 50 \text { individuals } \\
\text { Matrilines }\end{array}$ & $\begin{array}{l}1 \text { male for } 27 \text { females } \\
\text { Unrelated females }\end{array}$ \\
\hline Others & & + Human interventions: capture.... \\
\hline
\end{tabular}

Therefore, we investigated the potential effect of early experience by comparing long-tailed macaques in Fang Cheng Gang according to their origins: in this facility individual could be either captive-born and, as mentioned earlier submitted to early weaning, hence to maternal or successive peer separations, or wild-caught as adults and hence had experienced a normal ontogeny. Both categories were kept in separate social groups. We hypothesized that wild caught animals could have been "protected" when facing challenging situations, which is the case of the intensive husbandry system in which they were housed at the time of the observations. Hence, indicators of poor welfare, such as STB, should be more present in captive-born animals. We investigated whether adult play would follow the same pattern.

All the animals had been living in exactly the same conditions and on the same site for years, at the time of the beginning of the study and therefore, the animals differed only regarding their early experience.

Forty long-tailed macaques ( $N=40$ of each type) of FCG facility were observed according to the protocols described earlier. The results reveal a clear co-occurrence between play and STB. In captiveborn individuals (CB), both play and STB occurred with a high prevalence, respectively 99\% and 82.5\%) and co-occurrence (33/40 females performed both). All stereotypic females performed play. On the contrary, wild-caught animals (WC) showed a slightly lower prevalence of STB (60\%) but still more so play (70\%). Moreover, there was no systematic association between STB and play (Table 5).

Table 5

Co-occurrence of Play and Stereotypic Behaviors According to Early Experience

\begin{tabular}{lcccccc}
\hline & \multicolumn{3}{c}{ Captive Born } & \multicolumn{3}{c}{ Wild Caught } \\
\hline & Players & Non players & Total & Players & Non players & Total \\
STB & 33 & 0 & 33 & 17 & 7 & 24 \\
NSTB & 6 & 1 & 7 & 11 & 5 & 16 \\
Total & 39 & 1 & & 28 & 12
\end{tabular}

Note. Number of players (performed at least once play behavior) and non-players according to early experience being (STB) or not stereotype (NSTB) (stereotypic behavior observed at least once). 
The rates of STB and adult play also differed strikingly between WC and CB individuals, with CB females performing three times more play (Mann-Whitney-U test, $N=40, Z=3.70, p=0.0002$ ) and 7 times more STB than the WC females (Mann-Whitney-U test, $N=40, Z=4.15, p=0.00003$ ). This was observed for all types of STB (motor: $p=0.002$, oral: $p=0.0001$ ).

Interestingly, WC individuals were characterized by more occurrences of inactive state (Prolonged immobility with un focused gaze) (Mann-Whitney-U test, $N=40, Z=2.95, p=0.003$ ), maternal positive behaviors (Mann-Whitney-U test, $N=40, Z=3.18, p=0.001$ ), maintenance (i.e., scratching) (Mann-Whitney-U test, $N=40, Z=3.47, p=0.0004$ ) and agonistic behaviors (MannWhitney-U test, $N=40, Z=2.8670, p=0.004$ ), whereas CB individuals displayed more exploration (Mann-Whitney-U test, $N=40, Z=4.24, p=0.00001$ ).

\section{Conclusion}

The comparison of adult female macaques that had experienced different ontogenies before living in the same unfavorable conditions as adults again reveals that adult play and STB covary. Since, STB are more frequent in the $\mathrm{CB}$ animals, one can consider that the early management of the young monkeys (early separation, peer rearing) is a source of stress that makes them sensitive to future challenges, as reported in the literature for rodents or horses. This adult play covariation suggests that play may be a way of escaping from chronic stress and cannot be considered as a reliable indicator of positive welfare, in any case. Interestingly, while STB were also highly present in wild caught animals, this was less the case for play. This suggests that play, was still more dependent on early experience than STB, which deserves further investigation.

\section{Adult Play and Social Organization: Is There a Relationship?}

\section{The Importance of the Type of Social Organization in Cercopithecids}

Mancini and Palagi (2009) mentioned that in many species of cercopithecids, characterized by large groups including cohesive and structured relationships, play has not been reported. We took the opportunity to be able to work on different species of cercopithecids to compare the rate of adult play in naturalistic situations, between Campbell monkeys, a highly tolerant and fluid social species, mangabeys (white cheeked and red-capped mangabeys), with a more hierarchical type of society, and rhesus macaques, considered as "despotic" (Thierry, 1985).

\section{Material and Method}

The observations were performed using exactly similar protocol (for more detail see paragraph 2.1.b). They took place at the biological station of Paimpont for Campbell (ten adults), red-capped mangabeys (nine adults). Rhesus macaques were observed in a zoo (Planète Sauvage, Nantes, France). The behavior of 20 macaques $\left(N_{\text {male }}=5 ; N_{\text {female }}=15\right)$ was scored and recorded live by two trained observers, as in the Xierxin facility. In all situations, food was delivered in an equal manner in different parts of the enclosure.

\section{Results}

For all three species there were very few individuals exhibiting adult play behavior, in this situation of undisturbed stable groups, despite the many hours of observations: None of the Rhesus macaques adults and Campbell monkeys showed any play and 3 mangabeys showed some play (at a very low rate: from none to 2 ). 


\section{Conclusion}

These results show that spontaneous adult play does not arise in stable conditions, maybe because there is no need for social assessment, in a stable group, or there is not much social tension when food is delivered in an equal manner in different parts of the enclosure. Nevertheless in more challenging situations, long-tailed macaques exhibited more adult play than rhesus (see above), confirming interspecies differences.

Adult play behavior may need some kind of environmental or social challenge to appear. The social organization of the species is not sufficient to explain the prevalence, sometimes high, of adult play in some studies.

\section{Group Instability as a Major Factor of Emergence of Adult Play}

\section{In Horses \\ Material and Method}

We performed a study on 52 horses aged $3-17$ years old, of varied breeds and sex ( 2 stallions, 29 geldings and 21 mares), in Fall when they were in pastures in groups of five to fifteen individuals. Some of these groups were highly stable $(\mathrm{G} 1,2,6,7)$ and the horses had been going out together every day for at least 6 months, while others changed partners regularly when going out, according to the riding center's needs. The latter were then in a highly changing group composition. Each group was observed twice for two hrs and social interactions were noted ad libitum, while the identity and the distance of nearest neighbor were recorded using instantaneous scan sampling.

\section{Results}

Adult social play was observed at least once in 7 groups, but most play bouts were observed in G5, G7 and G8 (Fig. 5). This is interesting as these three groups corresponded to the most often modified groups that also have more work hours. With G6, they also corresponded to the groups that had larger distances between neighbors but also less social cohesion, as half of them had no preferred partner, a well-known feature of social cohesion in horses (Bourjade, Moulinot, Richard-Yris, \& Hausberger, 2008; Bourjade et al., 2009; Waring, 2003).

In Campbell monkeys (see Lemasson et al., 2005, 2006)

\section{Material and Method}

Behavioral observations were made on a captive group of 14 Campbell's monkeys that included seven adults (one male and 6 females), from January 1999 to June 2001. These observations were made during 8 different periods (Figure 6). Two types of periods can be distinguished: Periods without (A, C, and P5) and with (B, P1, P2, P3, and P4) social disturbances (removal of females, replacement of the male or birth of 2 babies). Each period lasted 10 to 12 days. Three observation sessions were performed every day (09:30-10:00 hr, 13:30-14:30 hr, and 16:30-17:00 hr). 


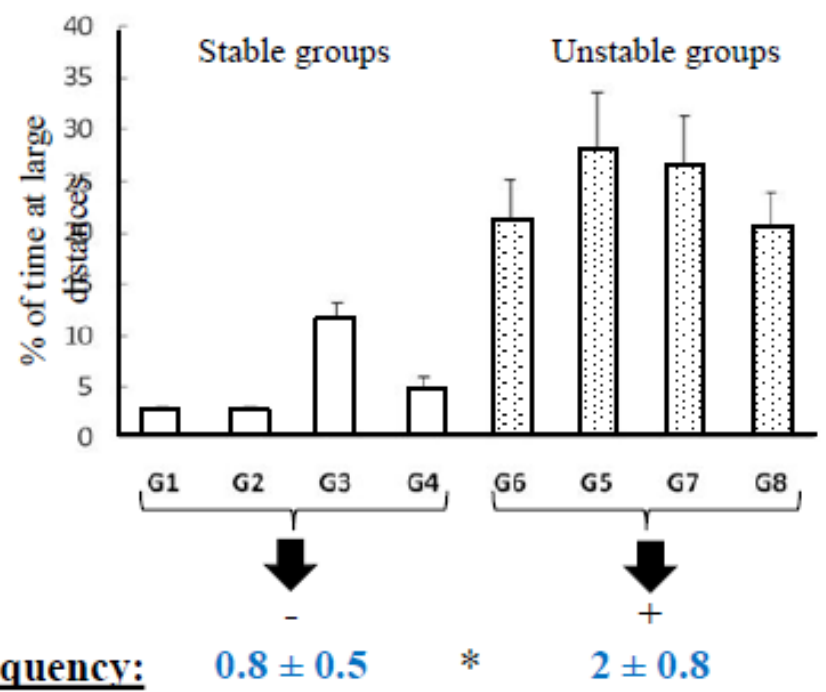

Figure 5. Comparison of play rate in stable and unstable (regular changes) groups of riding school horses observed in paddocks. Group cohesion of stable groups is revealed by little time spent at large distances. Instable groups have clearly higher adult play rates. *: Results of Mann-Whitney-U test.

\section{Results}

After each social change, the rate of aggressive behavior increased. In addition, aggression decreased strikingly from P4 to P5, after the group composition remained unchanged for a longer time. There was more play during the periods with disturbances $(3.41 \pm 1.21 \mathrm{SE}$ per day) compared to periods without disturbances $(1.19 \pm 0.56 \mathrm{SE}$ per day).

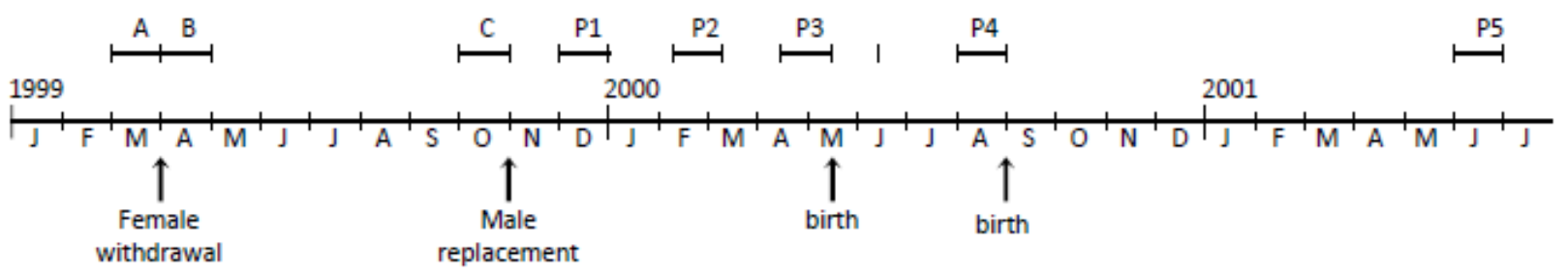

Figure 6. Time sequence of the observation sessions (A, B, C, P1, P2, P3, P4, and P5) and changes in group composition of Campell's monkeys, over 2 years. Two types of periods can be distinguished: periods without social perturbation (A, C and P5) and periods with (B, P1, P2, P3, and P4) social disturbances (removal of females, replacement of the male or birth of 2 babies). Each period lasted 10 or to 12 days. From Lemasson et al. (2006).

\section{Conclusion}

These data suggest that adult play may be triggered by social instability, which is reflected by the longer distances and the lower level of social bonding observed in horses and by the increased aggressive behaviors in monkeys. In horses, our results go along observations in the wild showing that the rare occurrences of adult play are mostly in stallions' bachelor groups, which are the less stable groups. One can hypothesize that play may help to evacuate stress or may enable to reduce tensions between the individuals (as in Mancini \& Palagi, 2009). 


\section{Discussion}

Our study of adult play in horses and cercopithecids species aimed at investigating whether adult play may be a reliable indicator of good welfare (Boissy et al., 2007; Spinka et al., 2011), a by-product of domestication or a tool for social cohesion in tolerant type societies of monkeys. Data from a domestic species (the horse) and wild/captive animals enabled us to confirm the literature data showing a greater prevalence (or even presence/absence) of adult play in both domestic and captive wild species. These findings argue against the idea that adult play may be a mere product of domestication, related to a "neotenic" origin of adult play. On the contrary, comparison of different life conditions revealed that in both horses and monkeys, adult play is more likely to arise in conditions that imply social/spatial/feeding restrictions. We demonstrated that animals living in naturalistic situations, without predators and with continuous access to (food) resources expressed the same low level as wild animals suggesting that captive/domestic animals do not play only because they are stress free (no predators) or well fed. Domestic/captive animals in naturalistic settings just spend their time foraging, resting and/or interacting. These observations led us to question the relation between adult play and welfare. Data on horses clearly indicate that play is not a reliable indicator of welfare: 1) Adult domestic horses in restricted domestic conditions play more than conspecifics that live in natural conditions; 2) within a population of riding school horses, the horses that played the most were also those that exhibited the greatest signals of poor welfare.

Interestingly, similar conclusions were drawn from our macaque studies. Not only did the adult macaques living in intensive husbandry play more, but a clear co-occurrence was observed between play and stereotypic behaviors, which are indicators of inappropriate living conditions in primates. These findings could be related to 1) the restricted access to time-limited resources and 2) the early life experiences. Captive born animals that had experienced early weaning (and often successive peer separations) were more likely to exhibit abnormal behaviors and play than wild born animals. Other aspects, such as physical obstacles were shown to increase both aggressiveness and adult play in cercopithecid species, indicating that adult play may be triggered by tensions and stress, as suggested by several authors (Fagen \& Fagen, 2004; Norscia \& Palagi, 2011; Palagi, 2007). We tested whether the prevalence of adult play in monkeys may reflect social organization and social bonding. Actually, none of the two species observed (rhesus macaques, Campbells' monkeys) and few individuals of the two species of mangabeys produced adult play when in naturalistic conditions and in stable groups. Increases of adult play did however occur at times of disturbances: Disappearance of familiar animals, arrivals of new animals. Thus, adult play was more frequent at times of social disturbances and instability, in horses and monkeys, suggesting it could be a general trend.

\section{A Finding: More Adult Play in Domestic/Captive Animals}

Play is a juvenile characteristic and has long been considered as such (Buytendijk, 1933 cited by Thinès 1996). In most species, play is at its peak a few days or weeks after birth, but a "zero-level" is reached around 30 days for a mouse (Byers \& Walker, 1995), 12 weeks for a pronghorn (Byers, 1997), a few months for a cat (West, 1974), around 5 years for a baboon (Owens, 1975). Our studied species conformed to this rule, as in natural conditions horses stop playing at around 5 years of age, at the latest, and cercopithecids show a negative correlation between age and play (as do chimpanzees) (MendozaGranados \& Sommer, 1995). What could explain this consensual observation that domestic and captive animals do play at adult stages (Bekoff \& Byers, 1981)? The privileged hypothesis was that domestication or captivity may promote a developmental retardation, the retention of neotenic characteristics (e.g., play) and diminished fear (Coppinger \& Smith, 1989; Himmler et al., 2013).When wild rats and long Evans rats live in the same conditions, young wild rats play less than their domestic counterparts (Himmler et al., 2013). Strains of rats may differ in their frequency and types of play (Reinhart, McIntyre, Metz, \& Pellis, 2006; Sivyi, Baliko, \& Bowers, 1997), while play frequency is influenced by paternal origin in foals (Wolff \& Hausberger, 1994). Carnivores tend to play more than 
herbivores (Burghardt, 2005). The idea that domestication, through intended or non-intended genetic selection, may have induced the persistence of juvenile features (amongst which play) at later stages is likely to be true and may explain why pet animals (dogs, cats) are particularly concerned.

However, our study, along with several previous reports (e.g., Sigursjondottir et al., 2003), shows that, when domestic animals, such as horses, live in naturalistic conditions, adult play rarely occurs. On the contrary, our macaque study showed that under intensive husbandry, wild species may develop adult play. Adult Przewalski horses also developed adult play in zoos (Budiansky, 1997). Another interpretation could be that adult play is higher in captive studies because of the removal of predation and foraging pressures (Graham, 2011). Again, this may be true, but the rhesus macaques and horses observed in naturalistic conditions, with no predation or food restriction, failed to exhibit adult play (as do Icelandic domestic horses, Sigurjonsdottir et al., 2003). Thus, this hypothesis cannot explain the observed differences between captive/domestic animals and feral/wild animals. Therefore, these observations raise two concerns:

1) To which extent can studies of play in captive/domestic animals be used for testing its adaptive significance? Most studies would just mix both situations (e.g., Graham, 2011).

2) What other alternative hypotheses could be proposed? Burghardt (2005) noticed that both adult play and stereotypic behaviors occur more frequently in the "barren/boring" environments provided by captive/domestic situations.

\section{Adult Play as an Indicator of Welfare?}

Play as an indicator of well-being has been such a consensual view that all the definitions of play include this concept as a core element (e.g., Bekoff \& Byers, 1981; Burghardt, 2005). Play behavior has long been proposed as an indicator of good welfare because it is generally associated with better welfare in younger stages (Boissy et al., 2007; Held \& Spinka, 2011; Newberry et al., 1988). However, even studies on juvenile stages lead to contradictory findings where social or feeding deprivation may lead to either a reduction of play (e.g., Donaldson et al., 2002) or its enhancement (e.g., Bateson et al., 1990).

As adult play is rare, it may moreover have a different functional significance from juvenile play. For Held and Spinka, "where adult play is naturally rare, its occasional occurrence most likely indicates the animal is currently faring well" (2011, p. 896). How can we explain then that captive adult animals in restricted conditions play more than conspecifics living in more "appropriate" conditions?

While more and more studies suggest a complex relationship between play behavior and stress (Biben \& Champoux, 1999; Palagi et al., 2004; Pellis \& Pellis, 2009) and wonder whether stressful situations invariably diminish play or whether they can actually enhance play (Pellis \& Pellis, 2009), the proper investigation of this question is blocked by the assertion that the definitions of play assume its association with a positive context. However while "the commonly held view is that play is suppressed by stress," recent studies indicate that it can also regulate stress (Palagi et al., 2004, p. 960).

One major obstacle for disentangling the complex relation between play and stress may be that acute versus chronic stress may act in opposite ways on play, especially on adult play. The recent study of Klein et al. (2010) reveals that acute restraint stress diminishes play in male rats, while a repeated chronic stress diminishes all social interactions, but not plays. This finding may be a key element for understanding the contradictory findings on adult play in the literature.

The example of horses is particularly enlightening here. The rare occurrences of adult play in the wild are periods of harsh weather conditions, social disturbances in bachelor groups of young stallions or solicitations by younger animals (e.g., Bourjade et al., 2009; Sigurjonsdottir et al., 2003). This was confirmed in our semi-natural group of male horses that the almost only performed play in December, when colder weather was present and resources were scarce (see above).

Other accounts of adult play in domestic horses deserve consideration. Rebound effects are common and lead horses living in single stalls to increase their locomotors activity and exhibit excited behaviors such as trot, canter but also bucking, prancing and other types of excited behavior patterns when given the opportunity (e.g., being released in a large arena) (e.g., Lesimple, Fureix, Le Scolan, 
Richard-Yris, \& Hausberger, 2011; Wolff, Le Scolan, \& Hausberger, 1997). For scientists performing temperament tests, such behaviors are clearly indicators of excitement and emotionality (e.g., Hausberger, Muller, \& Lunel, 2011). But for play specialists, these patterns of exaggerated locomotion and movements without any clear immediate function could easily be considered as locomotor play, as they are identified in the play repertoire of foals (McDonnell \& Poulin, 2002). Where does play start? How can we properly measure its conditions of occurrence? Is there a common feature in situations of restricted access to space and peers, excitement and play are ways of evacuating stress when the opportunity arises? In that case, observing an adult playing tells us that it is momentarily happier, but does not tell us anything about its welfare. The problem is less crucial for social play, when horses behave clearly differently between mock aggressions and real ones (although play fighting can change into real fights) (Bourjade et al., 2009; McDonnell \& Poulin, 2002), but again social deprivation leads to an increase of play fighting in young stallions when reunited with peers (Christensen et al., 2002). Such rebounds effects confirm that, in fact, play is an ambiguous indicator of welfare: In Christensen's study (2002) the young stallions that were raised along with peers did not show this increase. Should we consider that they were in a worse welfare state than the previously isolated individuals? In natural conditions (including stress free semi-natural conditions) when groups are stable, adult horses predominant activities are foraging, slow walking, resting, with very rare occurrences of 'excited' behaviors and play is absent. Does this mean that they experience poorer welfare state compared to their riding school counterparts?

There is no doubt that, at the precise time of play, animals (like humans) experience positive emotions, as play involves neurotransmitter systems that are also involved in the hedonic properties of food and drug rewards (opioids, cannabinoids and dopamine) (Trezza et al., 2011). It has been shown that opioids modulate social play by influencing its subjective positive properties (Trezza et al., 2010). These same systems are however also involved in compulsive games in humans (Frost, Steketee, \& Green, 2003) and wheel running in rodents (Sherwin, 1998). Parallels with stereotypic behavior, are interesting: Absence in wild/naturalistic situations, same neurotransmitter and brain global structures involved (basal ganglia/striatum: Graham, 2010). Burghardt (2005) suggested to consider a continuum from exploration (often interspersed with play) to play to stereotypies. Our data on macaque monkeys are here compelling. They revealed a clear relationship between the prevalence of STB and adult play in unfavorable husbandry conditions: Both were more present in some facilities than in others, both were sensitive to the same temporal context and to the same early life experiences. Adult "players" had more chances to be also stereotypic. These findings strongly support Burghardt's hypothesis and open new lines for further investigations on the possible common substrates and causalities.

What these results clearly reveal is that adult play cannot be considered as a "universal indicator of good welfare." Stereotypic behaviors occur mostly in unfavorable conditions (Mason, 1991; 1996) and are considered as a reliable indicator of a poor psychological well-being in primates (Crockett et al., 1995). Our findings on adult riding school horses (see also Hausberger et al., 2012) go along with this idea, because the "players" showed more signs of a poor welfare state than the non-players. The correlation between adult play and measures of oxidative stress are especially interesting.

In conclusion, while adult play may indicate that, at the present time, the situation has just improved (e.g., rebound effects after social isolation or spatial restriction), it is clear that adult play cannot be considered as a reliable welfare indicator that could help in evaluating whether or not management of the captive/domestic animals is appropriate. It is often associated with excitement, high arousal, which are not the usual state in which animals living in naturalistic, unrestricted and socially stable groups are observed. If adult play was considered as a welfare criterion, most ungulate populations living in such conditions would be considered as in poor welfare conditions.

\section{Adult Play and its Functional Significance}

Considering that play may, in some circumstances/species, reveal an altered welfare gives a new opening to its possible functions that remain so far a mystery (Burghardt, 2005; Pellis, Pellis, \& Bell, 2010). 
Adult play (like stereotypies) may relieve the sensory deprivation that can prevail in captive/domestic environments (Burghardt, 2005). Play may be a way of exposing an animal to new situations. In humans, chess players have a high sensation seeking profile (Joireman, Fick, \& Anderson, 2002). In foals, play is stimulated by novel conditions or stimuli and is often interspersed with exploration (McDonnell \& Poulin, 2002). However, in very restricted sensory conditions, horses may on the contrary become withdrawn, unresponsive (Fureix et al., 2012) or favor active locomotion over play when in group (Benhajali et al., 2008). Sensation seeking is certainly one possible causal factor but does not explain some of our results.

Adult play may be a way of coping with certain types of environmental stressors (Coe et al., 1989). Young rhesus monkeys play more when the troop is under stress (O'Neill-Wagner, 1994). It has also been proposed that stereotypic behaviors may be coping mechanisms. In both cases, there is still no evidence confirming this idea. It has been suggested that animals may use play as "self-medication" (Pellis \& Pellis, 2009) because of its association with endogenous opioids, that it favors emotional resilience by "training earlier for the unexpected" (Spinka et al., 2001, p. 143) and that it may be used as an escape (Burghardt, 2005). Unfortunately, there is scarce evidence of such effects. It has been shown that calves exhibiting tongue play have less erosive mouth ulcerations (Burghardt, 2005). Our data do not allow us to conclude on this aspect. Adult horse players were those that showed the most altered welfare, but they were given the possibility to express play only a few hours a week, while they were in restrained conditions 6 days a week, 24 hrs per day, which may not be enough for them to compensate. In macaques, since play and stereotypic behaviors co-occurred, we could not show that being a player may improve the welfare state, but the results do not allow us to formulate clear conclusions. Regarding the hypothesis of adult/captive play being an indicator of potential welfare problems, future research should clearly investigate the animal state at different stages and in different living conditions.

Another interesting hypothesis that would also account for rebound effects after social/spatial restrictions, proposes that play, through "circular and muscular reactions would remove toxic substances that build up in response to physical or mental work and stress" ("recuperation theory," Carr, 1902, p. 36). The finding that adult horse players showed the highest levels of oxidative stress, and that play frequency was correlated with measures of oxidative stress questions the possible role of play in oxygenation and evacuation of toxins.

\section{Adult Play: A Part of the Behavioral Repertoire?}

Our study, along with an abundant literature on a variety of primate species (Palagi et al., 2004), suggests that adult social play may be involved in tension reduction and creation of new bonds. But it most often (apart from maybe bonobos and geladas: Palagi et al., 2004) relates to stressful situations, social disturbance or instability (as shown in horses). However, many studies are performed on captive animals, and our findings show that many factors may influence the prevalence of adult play. Early experience is often disturbed in both captive and domestic animals: Pigs are weaned at 2-6 weeks (instead of 3-4 months) (Jensen \& Kyhn, 2000), rats at 21 days (instead of 35 - 42 days) (Mason \& Latham, 2004), foals at 4-6 months (instead of 9-10 months) (Henry et al., 2012), elephants at 3 years (instead of 7-12 years) (Clubb \& Mason, 2002), macaques are weaned at 6 months (instead of 1 year) (Camus et al., 2014) and calves are weaned at a few hours of life instead of 9-11 months (Veissier, Lamy, \& Le Neindre, 1990). Given the strong impact that early experience had on the prevalence of adult play in our macaques, any study in captive/domestic situation may be biased by this (sometimes unknown) early experience. In the horses studied here, nothing was known about their early life, although most would go through routine procedures that may impact their emotionality on a long term basis (Durier, Henry, Sankey, Sizun, \& Hausberger, 2012). Of course, there are differences between species. Despite differences between the social organizations of rhesus, long-tailed macaques, mangabeys and Campbell monkeys, we found the same general trend for adult play to be inexistent or limited in quiet, unrestricted situations, as was also the case in horses. 
Adult play has probably a different significance in different species and at different ages, but some generalities may help our understanding. Accepting that adult play is not just a sign of "having fun" (Spinka et al., 2001, p. 144) but also a sign showing that the adult organism needs to evacuate stress may help progressing in the understanding of its functions.

\section{Towards a Challenging View of Adult Play: Could Play be a Derived Activity?}

One challenging hypothesis proposes that play may be a "derived activity" (displacement). According to Tinbergen (1952), such activities are related to a "general excitement," are characterized by their unpredictability and emancipation from the context ("emancipation from normal situation"). They are generally performed in exaggerated movements and are ritualized. For Tinbergen, such displacement behaviors are a "form of defense against neurotic disorders of the CNS, enabling it to get rid of the surplus of impulses which would otherwise damage it ." (Tinbergen, 1952, p. 23).

Play bouts often include ritualized elements (e.g., canids' bow, Bekoff, 1995). They derive from "actual functional behaviors" but have more exaggerated forms, shorter durations (e.g., McDonnell \& Poulin, 2002; Nunes et al., 1999) and are certainly in many cases emancipated from the context. Adult play, given the elements developed in this paper, could well (like self-scratching (Palagi et al., 2004) or yawning (Fureix et al., 2011) be considered as a derived behavior (that potentially helps to reduce stress and to cope with otherwise unfavorable conditions) (see also Yanagi \& Berman, 2014).

\section{Acknowledgements}

We thank M. Bourjade, S. Swessel-Robert, C. Coste and Q. Li for helping with analyses and data collections, A. Rossard and P. Bec for taking care of the Paimpont primates, F. Joubaud helped with literature data. This work was supported by CCMSA (horses' observations) and by Motac Neuroscience Ltd (macaques' observations). We are most grateful to the managers and staff of the different facilities that opened their door to our studies: Riding schools, Fang Cheng Gang, Xierxin and Hannan Jingang primate breeding facilities, Planète sauvage (in particular M. Boye). We are grateful to Dr. A. Chapelain for correcting the English of this manuscript. We thank Dr. Stan Kuczaj to offer us the opportunity to write this paper.

\section{References}

Altmann, J. (1974). Observational study of behaviour - Sampling methods. Behaviour, 49, $227-267$.

Anderson, C. A., \& Bushman, B. J. (2002). Human aggression. Annual Review of Psychology 53, $27-51$.

Antonacci, D., Norscia, I., \& Palagi, E. (2010). Stranger to familiar: Wild strepsirhines manage xenophobia by playing. PLoS ONE, 5, pone.0013218, e13218. http://dx.doi.org/10.1371/journal.

Baldwin, J. D. (1986). Behavior in infancy: Exploration and play. Comparative Primate Biology, 2A, $295-326$.

Bateson, P., \& Young, M. (1981). Separation from the mother and the development of play in cats. Animal Behaviour, 29, 173-180.

Bateson, P., Mendl, M., \& Feaver, J. (1990). Play in domestic cats is enhanced by rationing of the mother during lactation. Animal Behaviour, 40, 514-525.

Bekoff, M. (1995). Play signals as punctuation: The structure of social play in canids. Behaviour, 132, 419-429.

Bekoff, M., \& Byers, J. A. (1981). A critical reanalysis of the ontogeny of mammalian social and locomotor play: An ethological hornet's nest. In K. Immelmann, G.W. Barlow, L. Petrinovich \& M. Main (Eds.), Behavioral development: The Bielefeld interdisciplinary project (pp. 296-337). New York: Cambridge University Press.

Bekoff, M., \& Byers, J. A. (1998). Animal play - Evolutionary, comparative and ecological perspectives. Cambridge, UK: Cambridge University Press.

Benhajali, H., Richard-Yris, M. A., Leroux, M., Ezzaouia, M., Charfi, F., \& Hausberger, M. (2008). A note on the time budget and social behaviour of densely housed horses - A case study in Arab breeding mares. Applied Animal Behaviour. Science, 112, 196-200.

Bernstein, I. S., \& Mason, W. A. (1963). Group formation by rhesus monkeys. Animal Behaviour, 11, $28-31$. 
Biben, M., \& Champoux, M. (1999). Play and stress: Cortisol as a negative correlate of play in Saimiri. In S. Reifel (Ed.), Play and culture studies, Vol. 2 (pp. 191-208). Westport, CT: Greenwood..

Blumstein, D. T., Chung, L. K., \& Smith, J. E. (2013). Early play may predict later dominance relationships in yellow-bellied marmots (Marmota flaviventris). Proceedings of the Royal Society, B Biological Sciences, 280, 20130485.

Boissy, A., Manteuffel, G., Jensen, M. B., Moe, R. O., Spruijt, B., Keeling, L. J., ...Aubert, A. (2007). Assessment of positive emotions in animals to improve their welfare. Physiology \& Behaviour, 9, 375-397.

Bourjade, M., de Boyer des Roches, A., \& Hausberger, M. (2009). Adult-young ratio, a major factor regulating social behaviour of young: A horse study. PLoS One, 4, e4888.

Bourjade, M., Moulinot, M., Richard-Yris, M. A., \& Hausberger, M. (2008). Could adults be used to improve social skills of young horses, Equus caballus? Developmental Psychobiology, 50, 408-417.

Brent, L., \& Viera, Y. (2002). Social behavior of captive indochinese and insular long-tailed macaques following transfer to new facility. International Journal of Primatology, 23, 147-159.

Budiansky, S. (1997). The nature of horses. New York: Free Press.

Burghardt, G. M. (2005). The genesis of animal play: Testing the limits. Cambridge, MA: MIT Press.

Burn, C. C., Dennison, T. L., \& Whay, H. R. (2010). Relationships between behaviour and health in working horses, donkeys, and mules in developing countries. Applied Animal Behaviour Science. 126, 109-118. doi: 10.1016/j.applanim.2010.06.007

Byers, J. A. (1997). American pronghorn. Social adaptation and the ghosts of predators past. Chicago: University of Chicago Press.

Byers, J. A. (1998). Biological effects of locomotor play: Getting into shape or something more specific? In M. Bekoff \& J. A. Byers (Eds). Animal play - Evolutionary, comparative and ecological perspectives (pp. 205220). Cambridge, UK: Cambridge University Press.

Byers, J. A., \& Walker, C. (1995). Refining the motor training hypothesis for the evolution of play. American Naturalist, 146, 25-40.

Cameron, E. Z., Linklater, W. L., Stafford, K. J., \& Minot, E. O. (2008). Maternal investment results in better foal condition through increased play behaviour in horses. Animal Behaviour, 76, 1511-1518.

Camus, S., Blois-Heulin, C., Li, Q., Hausberger, M., \& Bezard, E. (2013). Behavioural profiles in captive-bred cynomolgus macaques: Towards monkey models of mental disorders? Plos One, 8, e62141. doi: 10.1371/journal.pone.0062141

Camus, S., Rochais, C., Blois-Heulin, C., Li, Q., Hausberger, M., \& Bezard, E. (2013). Birth origin differentially affects depressive-like behaviours: Are captive-born cynomolgus monkeys more vulnerable to depression than their wild-born counterparts? PLoSONE, 8, e67711. doi: 10.1371/jour- nal.pone.0067711

Camus, S., Rochais, C., Blois-Heulin, C., Li, Q., Hausberger, M., \& Bezard, E. (2014). Depressive-like behavioural profiles in captive-bred single- and socially-housed rhesus and cynomolgus macaques: A species comparison. Frontiers in Behavioral Neuroscience, 8, 1-15.

Carr, H. A. (1902). The survival values of play. Investigations of the Department of Psychology and Education of the University of Colorado, 1(2), 1-47.

Christensen, J. W., Ladewig, J., Søndergaard, E., \& Malmkvist, J. (2002). Effetcs of individual versus group stabling on social behavior in domestic stallions. Applied Animal Behaviour Science, 75, 233-248.

Ciani, F., Dall'Olio, S., Tanyon, R., \& Palagi, E. (2012). Social tolerance and adult play in macaque societies: A comparion with different human cultures. Animal Behaviour, 84, 1313-1322.

Clubb, R., \& Mason, G. (2002). A review of the welfare of zoo elephants in Europe. Report commissioned by the RSPCA. Oxford: University of Oxford.

Coe, C. L., Lubach, G. R., Ershler, W. B., \& Klopp, R. G. (1989). Influence of early rearing on lymphocyte proliferation responses in juvenile rhesus monkeys. Brain. Behavior and Immunity, 3, 47-60. doi: 10.1016/0889-1591(89)90005-6

Coppinger, R. P., Glendinning, J. I., Torop, E., Matthay, C., Sutherland, M., \& Smith C. (1987). Degree of behavioral neoteny differentiates canid polymorphs. Ethology, 75, 89-108. doi: 10.1111/j.14390310.1987.tb00645.x

Coppinger, R. ., \& Smith, C. K. (1989). A model for understanding the evolution of mammalian behavior. In H. Genoways (Ed.). Current mammalogy, Vol. 2 (pp, 335-374). New York: Plenum.

Corino, C., Rossi, R., Musella, M., Cannata, S., \& Pastorelli, G. (2007). Growth performance and oxidative status in piglets supplemented with verbascoside and teupolioside. Italian Journal of Animal Science, 6, $292-294$. 
Crockett, C. M., Bowers, C. L., Shimoji, M., Leu, M., Bowden, D. M., \& Sackett, G. P. (1995). Behavioral responses of longtailed macaques to different cage sizes and common laboratory experiences. Journal of Comparative Psychology, 109, 368-383.

Crowell-Davis, S. L., Houpt, K. A., \& Kane, L. (1987). Play development in Welsh pony (Equus caballus) foals. Applied Animal Behaviour Science, 18, 119-131.

Davenport, R. K., \& Menzel, E. W. (1963). Stereotyped behavior of the infant chimpanzee. Archives of General Psychiatry, 8, 99-104.

Day, J. E. L., de Weerd, H. A. V., \& Edwards, S. A. (2008). The effect of varying lengths of straw bedding on the behaviour of growing pigs. Applied Animal Behaviour Science, 109, 249-260.

De Moffarts, B., Kirschvink N., Pincemail, J., \& Lekeux, P. (2005). Physiological and pathological impact of oxidative stress in the equine species. Annales de médecine vétérinaire, 149, 1-9.

Devinney B. J., Berman, C. M., \& Rasmussen, K. L. R. (2003). Individual differences in response to sibling birth among free-ranging yearling rhesus monkeys (Macaca mulatta) on Cayo Santiago. Behaviour, 140, 899-924.

Diener, A., (1985). Behaviour analysis of polecats ferrets during social play. Zeitschrift für Tierpsychology, 67, 179197.

Donaldson, T. M., Newberry, R. C., Spinka, M., \& Cloutier, S. (2002). Effects of early play experience on play behavior of piglets after weaning. Applied Animal Behaviour Science, 79, 221-231.

Dudink, S., Simonse, H., Marks, I., de Jonge, F. H., \& Spruijt, B. M. (2006). Announcing the arrival of enrichment increases play behaviour and reduces weaning-stress-induced behaviours of piglets directly after weaning. Applied Animal Behaviour Science, 101, 86-101.

Durier, V., Henry, S., Sankey, C., Sizun, J., \& Hausberber, M. (2012). Locomotor inhibition in adult horses faced to stressors: A single postpartum experience may be enough! Frontiers in Psychology, 3, doi: 10.3389/fpsyg.2012.00442

Fagen, R., \& Fagen, F. (2004). Juvenile survival and benefits of play behavior in brown bears, Ursus arctos. Evolutionary Ecology Research, 6, 89-102.

Feh, C. (2005). Relationships and communication in socially natural horse herd. In D. S. Mills \& S. M. McDonnell (Eds.), The domestic horse, the origins, development and management of its behaviour (pp. 83-93). Cambridge, UK: Cambridge University Press.

Feist, J. D., \& McCullough, D. R. (1976). Behaviour patterns and communication in feral horses. Zeitschrift für Tierzuchtung und Zuchtungsbiologie, 4, 337-373.

Fisler, G. F. (I967). Nonbreeding activities of three adult males in a band of freeranging rhesus monkeys. Journal of Mammalogy, 48, 70-78.

Fonseca, B. P. A., Alves, A. L. G., Nicoletti, J. L. M., Thomassian, A., Hussni, C. A., \& Mikail, S. (2006). Thermography and ultrasonography in back pain diagnosis of equine athletes. Journal of Equine Veterinary Science, 26, 507-516.

Fraser, A. F., \& Broom, D. M. (1990). Farm animals and welfare. London: CAB international.

Frost, R. O., Steketee, G., \& Green, K. A. I. (2003). Cognitive and behavioral treatment of compulsive hoarding. Brief Treatment and Crisis Intervention, 3, 323-338.

Fureix, C., Benhajali, H., Henry, S., Bruchet, A., Prunier, A. Coste, C., ...Jégo, P. (2013). Plasma cortisol and faecal cortisol metabolites concentrations in stereotypic and non-stereotypic horses: Do stereotypic horses cope better with poor environmental conditions? BMC Veterinary Research, 9. doi:10.1186/1746-6148-9-3.

Fureix, C., Gorecka-Bruzda, A., Gautier, E., \& Hausberger, M. (2011). Co-occurrence of yawning and stereotypic behaviour in horses Equus caballus. ISRN Zoology, ID 271209.

Fureix, C., Jégo, P., Henry, S., Lansade, L., \& Hausberger, M. (2012). Towards an ethological animal model of depression? A study on horses. PLoS ONE, 7, e39280. doi: 10.1371/journal.pone.0039280

Fureix, C., Jégo, P., Sankey, C., \& Hausberger, M. (2009). How horses (Equus caballus) see the world: Humans as significant objects. Animal Cognition, 12, 643-654.

Fureix, C., Menguy, H., \& Hausberger, M. (2010). Partners with bad temper: Reject or cure? A study of chronic pain and aggression in horses. PloS One, 5, e12434.

Graham, K. L. (2010). Virtually playful: Do massively multiplayer online role-playing games meet behavioral criteria of play? American Journal of Play, 3, 106-125.

Graham, K. L. (2011). Coevolutionary relationship between striatum size and social play in nonhuman primates. American Journal of Primatology, 73, 314-322.

Gross, K. (1898). The play of animals. Translated by E. L. Baldwin. New York: Appleton.

Guerra, R. F., Takase, E., \& Nunes, C. R. O. (1999). Play fighting of juvenile golden hamsters (Mesocricetus auratus): Effects of two types of social deprivation and day of testing. Behavioural Processes, 47, $139-151$. 
Hall, S. L., \& Bradshaw, J. W. S. (1998). The influence of hunger on object play by adults domestic cats. Applied Animal Behaviour Science, 58, 143-150.

Hall, C., Goodwin, D., Heleski, C., Randle, H., \& Waran, N. (2008). Is there evidence of learned helplessness in horses? Journal of Applied Animal Welfare Science, 11, 249-266.

Hausberger, M., Fureix, C., Bourjade, M., Wessel-Robert, S., Richard-Yris, M. A. (2012). On the significance of adult play: What does social play tell us about adult horse welfare? Naturwissenschaften, 99, 291-302. doi: 10.1007/s00114-012-0902-8.

Hausberger, M., Gautier, E., Biquand, V., Lunel, C., \& Jégo, P. (2009). Could work be a source of behavioural disorders? A study in horses. PLoS One, 4(10), e7625. doi:10.1371/journal.pone.0007625.

Hausberger, M., Henry, S., Larose, C., \& Richard-Yris, M. A. (2007). First suckling: A crucial event for motheryoung attachment? An experimental study in horses (Equus caballus). Journal of Comparative Psychology, $121,109-112$.

Hausberger, M., Muller, C., \& Lunel C. (2011). Does work affect personality? A study in horses. PLoS ONE, 6(2), e14659. doi:10.1371/journal.pone.0014659.

Hausberger, M., Roche, H., Henry, S., \& Visser, E. K. (2008). A review of the human-horse relationship. Applied Animal Behaviour Science, 109, 1-24.

Held, S. D. E., \& Spinka, M. (2011). Animal play and animal welfare. Animal Behaviour, 81, 891-899

Henry, S., Richard- Yris, M. A., Tordjman, S., \& Hausberger, M. (2009). Neonatal handling affects durably bonding and social development. PLoS One, 4, e5216.

Henry, S., Zanella, A. J., Sankey, C., Richard-Yris, M. A., Marko, A., \& Hausberger, M. (2012). Adults may be used to alleviate weaning stress in domestic foals (Equus caballus). Physiology \& Behavior, 106, 428-438.

Himmler, B. T., Stryjek, R., Modlinska, K., Derksen, S. M., Pisula, W., \& Pellis, S. M. (2013). How domestication modulates play behavior: A comparative analysis between wild rats and a laboratory strain of Rattus norvegicus. Journal of Comparative Psychology. Advance online publication. doi: 10.1037/a0032187.

Hoffmann, R. (1985). On the development of social behavior in immature males of a feral horse population (Equusprzewalskii caballus). Zeitschrift für Saugetierkunde International Journal of Mammalian Biology, 50, 302314.

Jeffcott, L. B. (1980). Disorders of the thoracolumbar spine of the horse. A survey of 443 cases. Equine Veterinary Journal, 12, 197-210.

Jensen, M. B., \& Kyhn, R. (2000). Play behaviour in group-housed dairy calves, the effect of space allowance. Appied Animal Behaviour Science, 67, 35-46.

Joireman, J. A., Fick, C. S., \& Anderson, J. W. (2002). Sensation seeking and involvement in chess. Personality and Individual Differences, 32, 509-515.

Khan, B. N. (2013). Impact of captivity on social behaviour of chimpanzee (Pan troglodytes). The Journal of Animal \& Plant Sciences, 23, 779-785.

Klein, Z. A., Padow, W. A., \& Romeo, R. D. (2010). The effects of stress on play and home cage behaviors in adolescent male rats. Developmental Psychobiology, 52, 62-70. doi: 10.1002/dev.20413

Lansade, L., Pichard, G., \& Leconte, M. (2008). Sensory sensitivities: Components of horse's temperament dimension. Applied Animal Behaviour Science, 114, 534-553.

Lemasson, A., Blois-Heulin, C., Jubin, R., \& Hausberger, M. (2006). Female social relationships in a captive group of Campbell's monkeys (Cercopithecus campbelli campbelli). American Journal of Primatology, 68, 11611170.

Lemasson, A., Gautier, J. P., \& Hausberger, M. (2005). A brief note on the effects of the removal of individuals on social behaviour in a captive group of Campbell's monkeys (Cercopithecus campbelli campbelli): A case study. Applied Animal Behaviour Science, 91, 289-296.

Lesimple, C., Fureix, C., Biquand, V., \& Hausberger, M. (2013). Comparison of clinical examinations of back disorders and humans' evaluation of back pain in riding school horses. BMC Veterinary Research, 9, 209.

Lesimple, C., Fureix, C., Le Scolan, N., Richard-Yris, M. A., \& Hausberger, M. (2011). Housing conditions and breed are associated with emotionality and cognitive abilities in riding school horses. Applied Animal Behaviour Science, 129, 92-99.

Loranca, A., Terrero, C., \& Salas, M. L. (1999). Development of play in neonatally undernourished rats. Physiology \& Behaviour, 66, 3-10.

Mancini, G., \& Palagi, E. (2009). Play and social dynamics in a captive herd of gelada baboons (Theropithecus gelada). Behavioural Processes, 82, $286 \mathrm{e} 292$.

Martin, R. A. (2002). Is laughter the best medicine? Humor, laughter and physical health. Current Directions in Psychological Science, 11, 216-220. 
Mason, G. J. (1991). Stereotypies and suffering. Behavioural Processes, 25, 103-115.

Mason, G. J. (1996). Early weaning enhances the later development of stereotypy in minks. In I. Duncan, T. Widowski, \& D. Haley (Eds.), Proceedings of the 30th International Congress of the ISAE (p. 16). Guelph, Canada: The International Society for Applied Ethology.

Mason, G. J., \& Green, P. C. (1962). The effects of social restriction on the behavior of rhesus monkeys: IV. Responses to a novel environment and to an alien species. Journal of Comparative and Physiological Psychology, 55, 363-368.

Mason, G. J., \& Latham, N. R. (2004). Can’t stop, won’t stop: Is stereotypy a reliable animal welfare indicator? Animal Welfare, 13, 57-69.

Mason, G. J., \& Rushen, J. (2006). Stereotypic behavior in captive animals: Fundamentals and applications for welfare ( $2^{\text {nd }}$ ed.). Wallingford, UK: CAB International.

McDonnell, M., \& Poulin, A. (2002). Equid play ethogram. Applied Animal Behaviour Science, 78, $263-290$.

McGreevy, P. D., Cripps, P. J., French, N. P., Green, L. E., \& Nicol, C. J. (1995). Management factors associated with stereotypic and redirected behavior in the thoroughbred horse. Equine Veterinary Journal, $27,86-91$.

Mendoza-Granados, D., \& Sommer, V. (1995). Play in chimpanzees of the Arnhem Zoo: Self-serving compromises. Primates, 36, 57e68.

Mills, D. S. (2005). Repetitive movement problems in the horse. In D. S. Mills \& S. M. McDonnell (Eds.), The domestic horse: The origins, development and management of its behaviour (pp. 212-227). Cambridge, UK: Cambridge University Press.

Mintline, E. M., Wood, S. L., de Passillé, A. M., Rushen, J., \& Tucker, C. B. (2012). Assessing calf play behavior in an arena test. Applied Animal Behaviour Science, 141, 101-107.

Mormède, P., Adanson, S., Aupérin, B., Beerda, B., Guémené, D., Malmkvist, J., ... Veissier, I. (2007). Exploration of the hypothalamic-pituary-adrenal function as a tool to evaluate animal welfare. Physiology \& Behaviour, 92, 317-339.

Newberry, R. C., \& Wood-Gush, D. G. M. (1988). Development of some behavior patterns in piglets under seminatural conditions. Animal Production, 46, 103-109.

Normansell, L., \& Panksepp, J. (1990). Effects of morphine and naloxone on play-rewarded spatial discrimination in juvenile rats. Developmental Psychobiology, 23, 75-83.

Norscia, I., \& Palagi, E. (2011). When play is a family business: Adult play, hierarchy, and possible stress reduction in common marmosets. Primates, 52, 101-104.

Novak, M. A., Meyer, J. S., Lutz, C., \& Tiefenbacher, S. (2006). Deprived environments: Developmental insights from primatology. In G. J. Mason \& J. Rushen (Eds.), Stereotypic animal behaviour: Fundamentals and applications to welfare (pp. 153-189). Wallingford, UK: CABI.

Nunes, S., Muecke, E. M., Anthony, J. A., \& Batterbee, A. S. (1999). Endocrine and energetic mediation of play. Behavior in free-living belding's ground squirrels. Hormones and Behavior, 36, 153-165.

Oliveira, A. F. S., Rossi, A. O., Silva, L. F. R., Lau, M. C., \& Barreto, R. E. (2010). Play behaviour in nonhuman animals and animal welfare issue. Journal of Ethology, 28, 1-5.

O'Neill-Wagner, P. L. (1994). When trying to get your monkeys to behave, try perches. Touch, 1, 6-8.

Owens, N. W. (1975). A comparison of aggressive play and aggression in free-living baboons Papio Anubis. Animal Behaviour, 23, 755-465.

Palagi, E. (2007). Play at work: Revisiting data focusing on chimpanzees (Pan troglodytes). Journal of Anthropological Sciences, 85, 153-164.

Palagi, E., Cordoni, G. \& Borgognini, S. M. T. (2004). Immediate and delayed benefits of play behaviour: New evidence from chimpanzees (Pan troglodytes). Ethology, 110, 949-962.

Palagi, E., Paoli, T., \& Borgognini Tarli, S. (2006). Short-term benefits of play behaviour: Conflict prevention in captive bonobos (Pan paniscus). International Journal of Primatology, 27, 1257-1270.

Panksepp, J., \& Beatty, W. W. (1980). Social deprivation and play in rats. Behavioral Neural Biology, 30, $197-206$.

Pellis, S. M., \& Iwaniuk, A. N. (1999). The problem of adult play fighting: A comparative analysis of play and courtship in primates. Ethology, 105, $783 \mathrm{e} 806$.

Pellis, S. M., \& McKenna, M. M. (1992). Intrinsic and extrinsic influences on play fighting in rats: Effects of dominance, partner's playfulness, temperament and neonatal exposure to testosterone propionate. Behavioural Brain Research, 50, 135-145. doi: 10.1016/S0166- 4328(05)80295-5

Pellis, S. M., \& Pellis, V. C. (2009). The playful brain: Venturing to the limits of neuroscience. Oxford: Oneworld Publications.

Pellis, S. M., Pellis, V. C., \& Bell, H. C. (2010). The function of play in the development of the social brain. American Journal of Play, 2, 278-296. 
Pellis, S. M., Pellis, V. C., \& Reinhart, C. J. (2010). The evolution of social play. In C. Worthman, P. Plotsky, D. Schechter, \& C. Cummings (Eds.), Formative experiences: The interaction of caregiving, culture, and developmental psychobiology. Cambridge, UK: Cambridge University Press.

Petit, O., \& Thierry, B. (1994). Reconciliation in a group of Guinea baboons (Papio papio). In J. J. Roeder, B. Thierry, J. R. Anderson, \& N. Herrenschmidt (Eds.), Current primatology, Vol. 2 (pp. 137-145). Strasbourg, France: Université Louis Pasteur.

Post, W., \& Baulu, J. (1978). Time budgets of Macaca mulatta. Primates, 19, 125-140.

Reamer, L., Tooze, Z., Coulson, C., \& Semple, S. (2010). Correlates of self-directed and stereotypic behaviours in captive red-capped mangabey (Cercocebus torquatus torquatus). Applied Animal Behaviour Science, 124, 68-74.

Reinhart, C. J., McIntyre, D. C., Metz, G., \& Pellis, S. M. (2006). Play fighting between kindling-prone (FAST) and kindling-resistant (SLOW) rats. Journal of Comparative Psychology, 120, 19-30. doi: 10.1037/ 07357036.120.1.19

Sherwin, C. (1998). Voluntary wheel running: A review and novel interpretation. Animal Behaviour, 56, 11-27.

Sigurjonsdottir, H., van Dierendonck, M. C., Snorrason, S., \& Thorhallsdottir, A. G. (2003). Social relationships in a group of horses without a mature stallion. Behaviour, 140, 783-804.

Sivyi, S. M., Baliko, C. N., \& Bowers, S. (1997). Rough-and-tumble play behavior in Fisher-344 and Buffalo rats: Effect of social isolation. Physiology \& Behaviour, 80, 385-394.

Smith, E. F. S. (1991). The influence of nutrition and post-partum mating on weaning and subsequent play behavior of hooded rats. Behavioral Brain Science, 5, 139-155.

Son, V. D. (2004). Time budgets of Macaca fascicularis in a mangrove forest, Vietnam. Laboratory Primate Newsletter, 43(3), 1-4.

Spinka, M., Newberry, R. C., \& Bekoff, M. (2001). Mammalian play: Training for unexpected. The Quarterly Review of Biology, 76, 141-168.

Thierry, B. (1985). Patterns of agonistic interactions in three species of macaque (Macaca mulatta, M. fascicularis, M. tonkeana). Aggressive Behavior, 11, 223e233.

Thinès, G. (1996). Le jeu - Le jeu chez l'enfant. Encyclopedia Universalis, 13, 33-37.

Tinbergen, N. (1952). Derived activities: Their causation, biological significance, origin, and emancipation during evolution. The Quarterly Review of Biology, 27, 1-32.

Trezza, V., Baarendse, P. J. J., \& Vanderschuren, L. J. M. J. (2010). The pleasures of play: Pharmacological insights into social reward mechanisms. Trends in Pharmacological Sciences, 31, 463-469.

Trezza, V., Damsteegt, R., Achterberg, E. J. M. \& Vanderschuren, L. J. M. J. (2011). Nucleus accumbens $\mu$-opioid receptors mediate social reward. The Journal of Neuroscience, 31, 6362-6370.

Turner, S. P., Ewen M., Rooke, J. A., \& Edwards, S. A. (2000). The effect of space allowance on performance, aggression and immune competence of growing pigs housed on straw deep-litter at different group sizes. Livestock Production Science, 66, 47-55.

van Hasselt, F. N., Tieskens, J. M., Trezza, V., Krugers, H. J., Vanderschuren, L. J., \& Joëls, M. (2012). Withinlitter variation in maternal care received by individual pups correlates with adolescent social play behavior in male rats. Physiology and Behavior, 106, 701-706.

van Hoof, J. A. R. A. M. (1967). The facial displays of the Catarrhine monkeys and apes. In D. Morris (Ed), Primate ethology (2006 ed.) (pp. 7-68). London: Wiedenfeld and Nicolson.

Veissier, I., Lamy, D., \& Le Neindre, P. (1990). Social behaviour in domestic beef cattle when yearling calves are left with the cows for the next calving. Applied Animal Behaviour Science, 27, 193-200.

Waring, G. (2003). Horse behavior (2nd ed.). New York: Noyes Publications/ William Andrew Publishing, Norwich.

Wells, S. M., \& von Goldschmidt-Rothschild, B. (1979). Social behavior and relationships in a herd of Camargue horses. Zeitschrift fur Tierpsychologie - Journal of comparative Ethology, 49, 363-380.

West, M. (1974). Social play in the domestic cat. American Zoologist, 14, 427-436.

Wolff, A., \& Hausberger, M. (1994). Behaviour of foals before weaning may have some genetic basis. Ethology, 96, $1-10$.

Wolff, A., Hausberger, M., \& Le Scolan, N. (1997). Experimental tests to assess emotivity in horses. Behavioural Processes, 40, 209-221.

Wood-Gush, D. G. M., Vestergaard, K., \& Petersen, H. V. (1990). The significance of motivation and environment in the development of exploration in pigs. Biology Behaviour, 15, 39-45.

Xu, F., Xie, L., Li, X., Li, Q., Wang, T., Ji, Y., ...Xie, P. (2012). Construction and validation of a systematic ethogram of Macaca fascicularis in a free enclosure. Plos one, 7, e37486. 
Blois-Heulin et al. 185

Yanagi, A., \& Berman, C. M. (2014). Body signals during social play in free-ranging Rhesus macaques (Macaca mulatta): A systematic analysis. American Journal of Primatology, 76, 168-179. 